\title{
Remediation of soil and groundwater contaminated with organic chemicals using stabilized nanoparticles: Lessons from the past two decades
}

\author{
Zhengqing Cai ${ }^{1,2 *}$, Xiao Zhao ${ }^{3 *}$, Jun Duan ${ }^{4 *}$, Dongye Zhao $(\varangle){ }^{4}$, Zhi Dang ${ }^{5}$, Zhang Lin ${ }^{5}$ \\ 1 National Engineering Lab for High-concentration Refractory Organic Wastewater, East China University of Science and Technology, \\ Shanghai 200237, China \\ 2 Shanghai Institute of Pollution Control and Ecological Security, Shanghai 200092, China \\ 3 College of Water Resources \& Civil Engineering, China Agricultural University, Beijing 100083, China \\ 4 Environmental Engineering Program, Department of Civil Engineering, Auburn University, Auburn, AL 36849, USA \\ 5 School of Environment and Energy, South China University of Technology, Guangzhou 510006, China
}

\section{H I G H L I G H T S}

- Overviewed evolution and environmental applications of stabilized nanoparticles.

- Reviewed theories on particle stabilization for enhanced reactivity/deliverability.

- Examined various in situ remediation technologies based on stabilized nanoparticles.

- Summarized knowledge on transport of stabilized nanoparticles in porous media.

- Identified key knowledge gaps and future research needs on stabilized nanoparticles.

\section{A R T I C L E I N F O}

\section{Article history:}

Received 16 March 2020

Revised 30 April 2020

Accepted 4 May 2020

Available online 15 June 2020

\section{Keywords:}

Stabilized nanoparticle

In-situ remediation

Organic contaminant

Soil remediation

Groundwater

Fate and transport

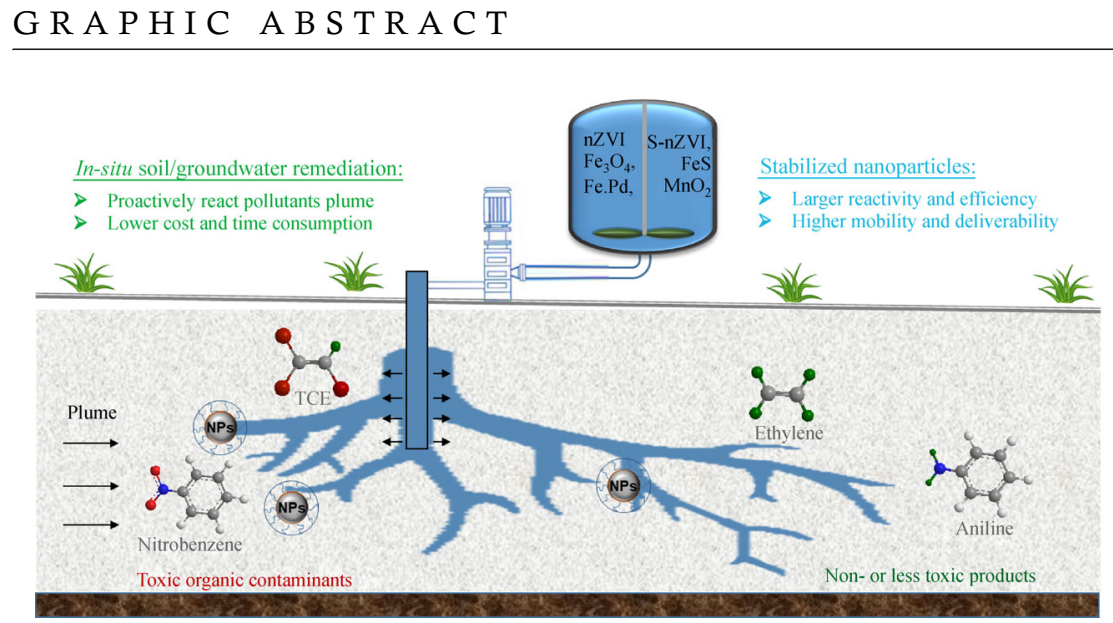

A B S T R A C T

Due to improved soil deliverability and high reactivity, stabilized nanoparticles have been studied for nearly two decades for in situ remediation of soil and groundwater contaminated with organic pollutants. While large amounts of bench- and field-scale experimental data have demonstrated the potential of the innovative technology, extensive research results have also unveiled various merits and constraints associated different soil characteristics, types of nanoparticles and particle stabilization techniques. Overall, this work aims to critically overview the fundamental principles on particle stabilization, and the evolution and some recent developments of stabilized nanoparticles for degradation of organic contaminants in soil and groundwater. The specific objectives are to: 1) overview fundamental mechanisms in nanoparticle stabilization; 2) summarize key applications of stabilized nanoparticles for in situ remediation of soil and groundwater contaminated by legacy and emerging organic chemicals; 3) update the latest knowledge on the transport and fate of stabilized nanoparticles; 4) examine the merits and constraints of stabilized nanoparticles in environmental remediation applications; and 5) identify the knowledge gaps and future research needs pertaining to stabilized nanoparticles for remediation of contaminated soil and groundwater. Per instructions of this invited special issue, this review is focused on contributions from our group (one of the pioneers in the subject field), which, however, is supplemented by important relevant works by others. The knowledge gained is expected to further advance the science and technology in the environmental applications of stabilized nanoparticles.

(C) The Author(s) 2020. This article is published with open access at link.springer.com and journal.hep. com.cn $\triangle$ Corresponding author

E-mail: zhaodon@auburn.edu

\footnotetext{
*These authors contributed equally to this work.
}

Special Issue - Accounts of Aquatic Chemistry and Technology Research (Responsible Editors: Jinyong Liu, Haoran Wei \& Yin Wang)

\section{Introduction}

Groundwater is a vital drinking water source in many parts of the world. For example, groundwater accounts for $18 \%$ of China's annual total water consumption $\left(610\right.$ billion $\left.\mathrm{m}^{3}\right)$ 
(O'Carroll et al., 2013; MWR, 2015), and makes up one third of potable water supplies in England (WHO, 2006). Yet, with the rapid urbanization and industrialization over the past decades, large volumes of soil and groundwater have been contaminated by various legacy and emerging organic chemicals. For instance, in China, the widespread environmental pollution has caused extensive groundwater contamination, and $\mathrm{ca} .80 \%$ of the extractable shallow groundwater was found polluted (MEE, 2016).

Of the various priority contaminants, chlorinated solvents such as trichloroethene (TCE), tetrachloroethene (PCE), and carbon tetrachloride (TeCA) have been the most widely studied legacy pollutants in soil and groundwater. For instance, TCE was detected in over 1000 of the 1699 Superfund Sites in the US, and according to a US Geological Survey report, PCE, TCE and TeCA were detected in $8.9 \%, 5.1 \%$ and $4.7 \%$, respectively, of the $>5000$ wells studied throughout the conterminous United States (Moran et al., 2007). Due to continued uses in many industrial sectors, thousands of sites have been found contaminated with chlorinated solvents throughout Asia, Europe and other industrialized areas in the world over the past decades, and the concentration of the chlorinated solvents in groundwater was found to reach the $\mathrm{mg} / \mathrm{L}$ level (Azzellino et al., 2019; Squillace and Moran, 2007).

In addition, numerous other legacy and emerging organic contaminants have been detected in contaminated soil and groundwater, such as pesticides, dioxins, polychlorinated biphenyls (PCBs), polycyclic aromatic hydrocarbons (PAHs), pharmaceuticals and personal care products (PPCPs), flame retardants, and plasticizers. For examples, PAHs were found in $>600$ of the 1408 National Priorities List sites designated by the US Environmental Protection Agency (EPA) (Duan et al., 2015). A recent study in Ireland revealed that mecoprop, phenoxyacetic acid, and 2,4-dichlorophenol were detected in 36\%, 39\%, and $26 \%$ of the 730 groundwater samples collected in 6 agricultural sites (McManus et al., 2017). According to a national reconnaissance of pharmaceuticals and other organic contaminants in the US groundwater, which analyzed groundwater samples from a network of 47 sites across 18 states, organic contaminants were detected in $81 \%$ of the samples, with the most frequently detected compounds including $N, N$-diethyltoluamide (35\%), bisphenol A (30\%), tri(2-chloroethyl) phosphate (30\%), sulfamethoxazole (23\%), and 4-octylphenol monoethoxylate (19\%) (Barnes et al., 2008). More recently, per- and polyfluoroalkyl substances (PFAS) have been found at more than 400 military sites in the US.

These organic chemicals are often recalcitrant to natural degradation and can be retained in soil and groundwater for decades or even hundreds of years, causing long-term threat to the environmental and human health.

To mitigate the associated environmental risks, various remediation methods have been studied or applied to remove or degrade organic contaminants in soil and groundwater, including pump and treat (P\&T), permeable reactive barriers (PRBs), soil replacement, soil washing, electrokinetic removal/degradation, phytoextraction, and thermal treatment (Gong et al., 2018). For instance, since the 1980 s, P\&T has been widely applied to contaminated sites; but this ex-situ technique suffers from poor efficiency, contaminant redound, tailing and back diffusion, long remediation time, and high energy consumption (O'Connor et al., 2018). Likewise, since its invention in the 1990s, PRBs have been widely employed in the subsurface to intercept and transform contaminants in groundwater (Obiri-Nyarko et al., 2014). In 1991, O'Hannesin and Gillham (1992) applied granular zero valent iron (ZVI) in a PRB for in situ removing TCE and PCE in groundwater. Other than ZVI, many other materials have been tested for in situ remediation of groundwater contaminated with halogenated organics, phenolic compounds, pharmaceuticals, and nitroaromatics (Guan et al., 2015). For instance, zeolite (Vignola et al., 2011), calcite (Turner et al., 2008), pyrite (Wang et al., 2020), combined calcium peroxide and straw/biochar (Liu et al. 2019) have been used or tested as PRB filling materials. In addition, biochar (Tang et al., 2013), mackinawite (FeS) (Jeong and Hayes, 2007; Duan et al., 2019b), FeS-modified ZVI (Duan et al., 2019a; Kim et al., 2011; 2013), and $\mathrm{MnO}_{2}$ activated persulfate (Mazloomi et al., 2016) have been tested to remediate soil and groundwater contaminated with organic pollutants. However, PRBs are held back not only by the high installation cost, but also the reactive lifetime of the active materials, and may not be suitable for many soil geological and hydraulic conditions; and the bulk materials are limited to only amending surface soil for the poor deliverability in soil.

Over the last two decades or so, the development of innovative nanomaterials, in particular, stabilized nanoparticles, has brought about some major changes in groundwater and soil remediation. Stabilized nanoparticles offer some unprecedented advantages over traditional bulk materials, including much larger specific surface area, higher activity, and soil deliverability. Especially, because of the improved soil transportability, stabilized nanoparticles can be directly delivered into the source zone in contaminated soil or deep aquifers to destroy the contaminants in situ (Gong et al., 2018). Figure 1 shows a conceptualized schematic of in situ dechlorination of TCE and polychlorinated biphenyls (PCBs) as well as reduction of nitrobenzene by injection of stabilized ZVI nanoparticles into the contaminated source area. Compared to conventional remediation technologies, the in situ remediation by stabilized nanoparticles offers some key advantages, including: 1) it is less destructive and more cost effective, 2) it can proactively attack pollutants in source zones, and thus cuts down the remediation timeframe (Karn et al., 2009; Zhao et al., 2016), and 3) it 
can reach contaminant plumes in deep aquifers or in areas where conventional technologies cannot be applied.

The concept of direct injection of nanoscale ZVI (nZVI) for in situ dechlorination in the subsurface was first proposed in 1997 by Wang and Zhang (1997). After 4 years, Elliott and Zhang (2001) conducted the first field test for in situ dechlorination by delivering non-stabilized bimetallic $(\mathrm{Fe} / \mathrm{Pd})$ particles into a contaminated subsurface. However, this study and many follow-on studies revealed that the nanoparticles are prone to rapid aggregation, hindering the transport and deliverability of the nanoparticles (Elliott and Zhang, 2001).

To facilitate particle delivery, various particle stabilization methods have been investigated in the past 20 years. Typically, some macromolecules are coated on the surface of nanoparticles either during the nanoparticle formation (pre-aggregation stabilization) or after the particles (postaggregation stabilization) are formed, and the resulting electrostatic or/and steric repulsion forces keep the nanoparticles from aggregation (Zhao et al., 2016). The earliest work on the particle stabilization for environmental applications was for stabilizing ZVI nanoparticles, where Zhao and coworkers at Auburn University first invented a method for preparing highly stable ZVI nanoparticles by adding a low cost stabilizer (starch or carboxymethyl cellulose (CMC)) during the particle synthesis (He and Zhao, 2005,2007). The resulting nanoparticles have been considered the most deliverable ZVI nanoparticles so far, and have been tested or applied in several field scale tests or practices for in situ degradation of chlorinated solvents in soil and groundwater (see Section 3.1). Following the similar particle stabilization mechanisms, our group and others have also developed several other stabilized nanoparticles, such as $\mathrm{Fe}_{3} \mathrm{O}_{4}, \mathrm{FeS}, \mathrm{Fe}-\mathrm{Mn}$ binary oxides, and $\mathrm{Fe}_{3}\left(\mathrm{PO}_{4}\right)_{2}$.

Stabilized nanoparticles offer some unique features over conventional granular or powder materials, including: 1) stabilized nanoparticles remain dispersible in water and soil, maximizing soil deliverability and the specific surface area and reactivity of the nanoparticles, 2) the particle size, transportability and reactivity may be manipulated by using stabilizers of different physical-chemical properties (e.g., molecular weight, degree of substitution, functional groups, and hydrophobicity), especially when the preaggregation stabilization technique is applied (Zhao et al., 2016), and 3) stabilized nanoparticles may be directly delivered into the source zones to remediate contaminated soil/groundwater in situ.

Numerous bench-scale studies have been reported over the last decade or so to demonstrate the effectiveness of stabilized nanoparticles for potential in situ degradation of organic contaminants in soil and groundwater ( $\mathrm{He}$ et al., 2007; Wei et al., 2010; Swindle et al., 2014). In addition, increasingly more field-scale studies have been also carried out, which have unveiled the pros and cons of the nanoparticle-based in situ remediation technologies
(O'Carroll et al., 2013; Wu and Zeng, 2018). While these studies have demonstrated tremendous potential of the stabilized nanoparticles, they also revealed some challenges in the engineering applications, including: 1) highly stable and well dispersed nanoparticles are required to facilitate delivery of the nanoparticles in the subsurface and to avoid plugging the porous media; 2) the mobility of the injected nanoparticles need to be further improved to achieve homogeneous distribution of the nanoparticles in the target zones with a significant radius of active zone; 3) the long-term impacts on the local biogeochemical conditions remain poorly understood; and 4) the long-term fate and transport of the delivered nanoparticles need to be investigated.

Overall, this work aims to critically overview the evolution and some recent development of stabilized nanoparticles for degradation of organic contaminants in soil and groundwater. The specific objectives are to: 1) overview fundamental mechanisms in nanoparticle stabilization; 2) summarize key applications of stabilized nanoparticles for in situ remediation of soil and groundwater contaminated by legacy and emerging organic chemicals; 3) update the latest knowledge on the environmental impacts, fate and transport of stabilized nanoparticles; 4) address the merits and constraints of stabilized nanoparticles in environmental remediation applications; and 5) examine the knowledge gaps and future research direction of stabilized nanoparticles for remediation of contaminated soil and groundwater.

Per instructions of this invited special issue, this review is focused on contributions from our group, which, however, is supplemented by important relevant works by others. The knowledge gained is expected to further advance the science and technology in the environmental applications of stabilized nanoparticles.

\section{Stabilized nanoparticles}

\subsection{Basic chemistry for synthesis of engineered nanoparticles}

Generally, there are two strategies to fabricate nano-sized particles (Wiesner and Bottero, 2007; Zhao et al., 2016), including 1) top-down, namely to break down the large pieces of materials into nano-sized particles through physical methods such as ball-milling and grinding; and 2) bottom-up, namely to build up the nano-sized materials from atomic or molecular entities. The bottom-up approach has been more commonly used to prepare nanoparticles with better controlled properties, and thus will be the focus in this review.

Typically, iron-based nanoparticles, such as ZVI, magnetite and $\mathrm{FeS}$, are synthesized through redox reactions and/or precipitation processes in aqueous solution starting with $\mathrm{Fe}^{2+}$ and/or $\mathrm{Fe}^{3+}$. The formation of 


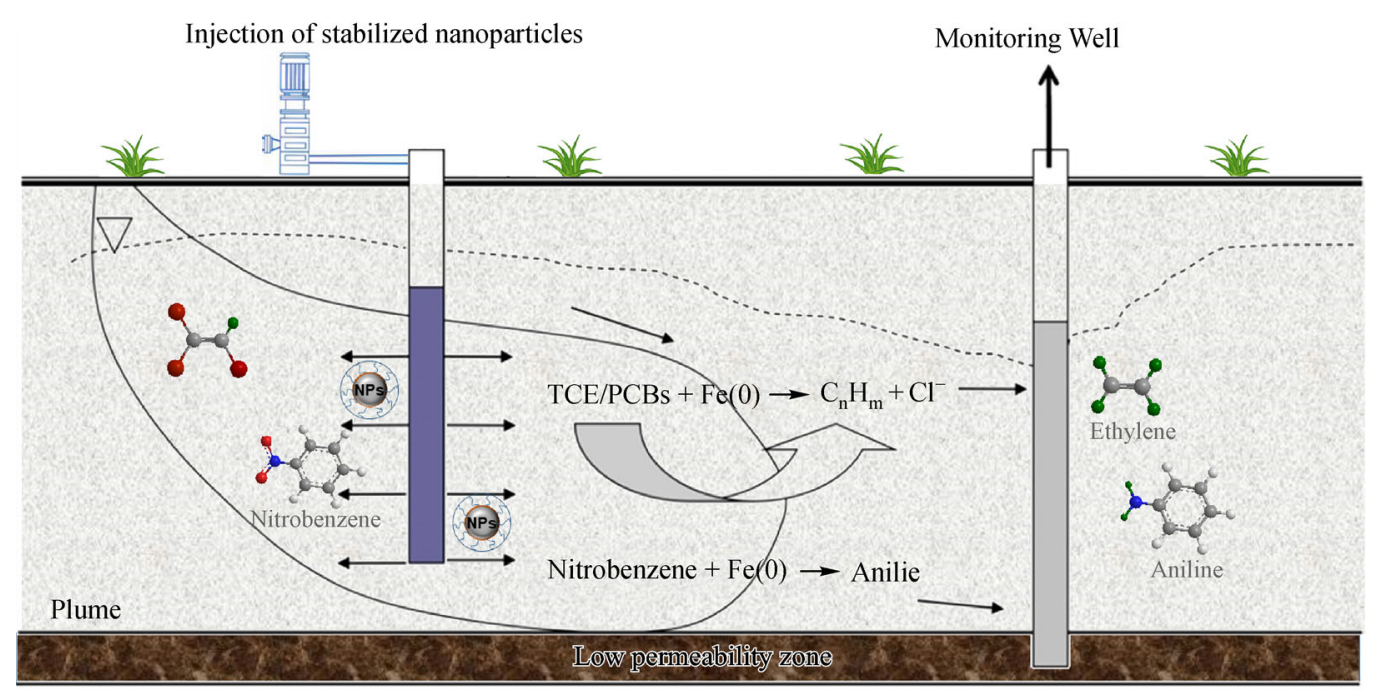

Fig. 1 Schematic description of in situ remediation of TCE/PCBs and nitrobenzene by directly delivering stabilized nZVI into contaminated source zone.

nanoscale clusters typically undergoes 4 steps (Wiesner and Bottero, 2007): 1) formation of zero-charged precursors, usually with redox reactions, hydroxylation and complexation involved; 2) nucleation, namely the zerocharged precursors assemble and condense through olation or oxolation; 3) growth of the nuclei to saturation or solubility limit for the precursors; and 4) aging stage, at which the minimum activation energy is reached and thermodynamically stable clusters/nanoparticles are formed. To produce nanoparticles with desired size, crystalline structure, and morphology, all of these 4 steps should be well-controlled.

For environmental applications (e.g., water treatment and soil remediation), several key criteria must be taken into account in the material synthesis, including: 1) the nanoparticles must be non-toxic, 2) the synthesis should avoid uses of toxic and expensive organic solvents, i.e., aqueous solution based synthesis is preferred, and 3) the overall process should be simple, low-cost and environmentally benign.

In line with these criteria, iron-based nanomaterials have been the most preferred nanomaterials for environmental uses, such as ZVI, iron sulfide $(\mathrm{FeS})$, magnetite $\left(\mathrm{Fe}_{3} \mathrm{O}_{4}\right)$, iron phosphate $\left(\mathrm{Fe}_{3}\left(\mathrm{PO}_{4}\right)_{2}\right)$, binary metal oxides $(\mathrm{Fe}-\mathrm{Mn}$ oxides), and sulfidated ZVI (S-nZVI).

ZVI has been the most studied iron-based nanoparticles (Liu et al., 2015). Nano-sized ZVI materials (typically aggregates of nanoscale primary particles) can be synthesized through high energy ball-milling (a top-down method), or reductive precipitation (bottom-up), or gasphase reduction of nanoscale iron oxide (Zhao et al., 2016). Wang and Zhang (1997) pioneered the use of ZVI for treating chlorinated solvents in water, where clustered ZVI particles were prepared by reducing Fe(III) using $\mathrm{NaBH}_{4}$. Since then, the borohydride reduction method has been widely used, though different precursors and reducing agents have also been employed (Zhao et al., 2016). Equation (1) illustrates the reductive formation of elemental $\mathrm{Fe}^{0}$ from $\mathrm{Fe}(\mathrm{II})$ or $\mathrm{Fe}(\mathrm{III})$.

$$
\mathrm{Fe}^{2+}\left(\text { or } \mathrm{Fe}^{3+}\right)+\text { reducing agent } \rightarrow \mathrm{Fe}^{0}
$$

The nucleation of the resulting $\mathrm{Fe}^{0}$ gives the clustered ZVI particles or aggregates. Typically, inert or anoxic conditions are desired during the synthesis to assure efficient reduction and avoid oxidation of the ZVI particles. Sodium/potassium borohydride is a strong reducing agent but comes with a relatively high cost. Consequently, some cheaper and "greener" reducing agents were also tested such as tea-based polyphenolic compounds (Hoag et al., 2009) or sorghum bran extracts (Njagi et al., 2011), but the resulting ZVI nanoparticles exhibited different morphologies and size distributions and weakened reactivity due to the slower nucleation and particle growth rates.

FeS nanoparticles have drawn extensive interests in environmental remediation recently for the moderate reducing power, longer-lasting reactive life than ZVI, and strong sorption capacity toward many heavy metals (Gong et al., 2016a). Conventionally, FeS nanoparticles can be synthesized through mixing stoichiometric amounts of $\mathrm{Fe}(\mathrm{II})$ and $\mathrm{S}^{2-}$ under inert or anoxic conditions as shown in Eq. (2) (Gong et al., 2016a),

$$
\mathrm{Fe}^{2+}+\mathrm{S}^{2-} \rightarrow \mathrm{FeS}
$$

Magnetite $\left(\mathrm{Fe}_{3} \mathrm{O}_{4}\right)$ nanoparticles have been shown to offer high adsorption capacities toward many important contaminants such as arsenic and chromium due to the larger specific surface area (Liang et al., 2012; Liang and Zhao, 2014). Generally, magnetite particles are prepared 
per the classical precipitation approach (Anderson, 1956). Typically, a base solution $\left(\mathrm{NaOH}\right.$ or $\left.\mathrm{NH}_{3}\right)$ is introduced dropwise into the solution containing $\mathrm{Fe}$ (III) and $\mathrm{Fe}$ (II) at a molar ratio of 2:1, thereby transforming $\mathrm{Fe}(\mathrm{III})$ and $\mathrm{Fe}(\mathrm{II})$ into $\mathrm{FeOOH}$ and $\mathrm{Fe}(\mathrm{OH})_{2}$, respectively, as shown in Eqs. (3) and (4). During the follow-on aging stage, $\mathrm{FeOOH}$ reacts with $\mathrm{Fe}(\mathrm{OH})_{2}$ to form the magnetite particles Eq. (5).

$$
\begin{gathered}
\mathrm{Fe}^{3+}+3 \mathrm{OH}^{-} \rightarrow \mathrm{Fe}(\mathrm{OH})_{3} \rightarrow \mathrm{FeOOH}+\mathrm{H}_{2} \mathrm{O} \\
\mathrm{Fe}^{2+}+2 \mathrm{OH}^{-} \rightarrow \mathrm{Fe}(\mathrm{OH})_{2} \\
2 \mathrm{FeOOH}+\mathrm{Fe}(\mathrm{OH})_{2} \rightarrow \mathrm{Fe}_{3} \mathrm{O}_{4}+2 \mathrm{H}_{2} \mathrm{O}
\end{gathered}
$$

Iron or calcium phosphate compounds have been found effective for sequestrating heavy metals such as $\mathrm{Pb}^{2+}$ and $\mathrm{Cu}^{2+}$ through the formation of metal phosphate precipitates and surface complexation (Liu and Zhao, 2007, 2013). Liu and Zhao (2007) synthesized iron phosphate nanoparticles through a straightforward stoichiometric precipitation approach per Eq. (6) (Liu and Zhao, 2007),

$$
3 \mathrm{Fe}^{2+}+2 \mathrm{PO}_{4}^{3-}+8 \mathrm{H}_{2} \mathrm{O} \rightarrow \mathrm{Fe}_{3}\left(\mathrm{PO}_{4}\right)_{2} \cdot 8 \mathrm{H}_{2} \mathrm{O}
$$

Binary metal oxides are commonly found in lithosphere and pedosphere, and show high affinity to metalloid anions (As or Se oxyanions). Fe-Mn binary oxides have been the most studied binary particles for treating arsenic and other metal/metalloids in water. Typically, Fe-Mn binary oxides particles are prepared by reacting $\mathrm{Fe}(\mathrm{II})$ with $\mathrm{KMnO}_{4}$ to form a mixed phase of $\mathrm{Fe}_{2} \mathrm{O}_{3}$ and $\mathrm{MnO}_{2}$, following the stoichiometry of Eqs. (7) and (8) (An and Zhao, 2012),

$$
\begin{gathered}
3 \mathrm{Fe}^{2+}+\mathrm{MnO}_{4}^{-}+4 \mathrm{OH}^{-}+3 \mathrm{H}_{2} \mathrm{O} \\
\rightarrow 3 \mathrm{Fe}(\mathrm{OH})_{3}+\mathrm{MnO}_{2}+\mathrm{H}^{+} \\
2 \mathrm{Fe}(\mathrm{OH})_{3} \rightarrow \mathrm{Fe}_{2} \mathrm{O}_{3}+3 \mathrm{H}_{2} \mathrm{O}
\end{gathered}
$$

S-nZVI has been recently synthesized through one-step or two-step synthesis method to enhance the reactivity and selectivity of pristine ZVI (Kim et al., 2011; Gong et al., 2017; Duan et al., 2019a). In the one-step method, a mixture of boronhidride and dithionite solution is dropwise added to the $\mathrm{Fe}^{3+}$ solution. The dithionite decomposes through Eqs. (9)-(11) to produce sulfide (Kim et al., 2011), and $\mathrm{Fe}^{0}$ and $\mathrm{FeS}$ were simultaneously formed via Eqs. (1) and (2) in one pot,

$$
\begin{gathered}
2 \mathrm{~S}_{2} \mathrm{O}_{4}^{2-}+\mathrm{H}_{2} \mathrm{O} \rightarrow 2 \mathrm{HSO}_{3}^{-}+\mathrm{S}_{2} \mathrm{O}_{3}^{2-} \\
\mathrm{S}_{2} \mathrm{O}_{4}^{2-}+\mathrm{S}_{2} \mathrm{O}_{3}^{2-}+2 \mathrm{H}_{2} \mathrm{O}+\mathrm{H}^{+} \\
\rightarrow 3 \mathrm{HSO}_{3}^{-}+\mathrm{H}_{2} \mathrm{~S}
\end{gathered}
$$

$$
\mathrm{H}_{2} \mathrm{~S} \rightarrow 2 \mathrm{H}^{+}+\mathrm{S}^{2-}
$$

In the two-step method, $\mathrm{Fe}^{0}$ is first formed according to Eq. (1), then a sulfur source is introduced to react with remaining $\mathrm{Fe}^{2+}$ to form $\mathrm{FeS}$ via Eq. (2) but in the presence of $\mathrm{Fe}^{0}$, resulting in a core-shell structure $\mathrm{FeS}-\mathrm{on}-\mathrm{Fe}^{0}$ particles (Duan et al., 2019a).

\subsection{Principles of nanoparticle stabilization}

In the nanoscale, surface forces far exceed gravity. As such, surface interactions dominate the physical stability of the nanoparticles. Moreover, nanoparticles possess very high surface energy and thus are thermodynamically unstable, i.e., they tend to agglomerate into larger particles and/or react with the media. Agglomeration of nanoparticles usually occurs in three manners (Zhao et al., 2016), including 1) Ostwald ripening, i.e., smaller or 'immature' particles may dissolve and become feeding materials for larger particles, leading to an increase of the mean particle size; 2) arrested precipitation (precipitation facilitated by formation of nucleation centers); and 3) attractive interactions between particles (e.g., van der Walls and magnetic forces).

Depending on the extent, aggregation can alter the physico-chemical properties of the particles and affect the environmental uses of nanoparticles. For instance, aggregated nanoparticles may partially or completely lose the characteristics of nanoscale particles such as high specific surface area, high reactivity, high-surface-to-volume ratio, and size-dependent physico-chemical properties. In addition, aggregated nanoparticles are much less transportable in soil or sediment (He et al., 2007). Consequently, particle stabilization is often required to resist aggregation and to obtain a stable dispersion for intended uses.

According to the classic Derjaguin-Landau-VerweyOverbeek (DLVO) theory, the net interaction energy between particles is the sum of repulsive energy and attraction energy (Phenrat et al., 2008). Typical attractive forces include van der Waals and magnetic attraction, whereas repulsive forces include electrostatic double layer repulsion, osmotic repulsion and elastic-steric repulsion. Coating nanoparticles with a proper stabilizers and at an appropriate concentration can increase the energy barrier between two approaching nanoparticles by enhancing the repulsive forces.

A stabilizer can function in two ways to increase the dispersion stability: 1) surface modification, i.e., charged stabilizer molecules are attached to particle surfaces, inducing electrostatic repulsion between like-charged surfaces; and 2) network or steric stabilization, i.e., stabilizer molecules (usually long-chained macromolecules) are attached on the surface to form a network to induce steric or osmotic separation of the nanoparticles. Accordingly, three particle stabilization mechanisms are often cited, namely, 1) electrostatic stabilization (charged 
stabilizers are sorbed on the surface to create/enhance the electrostatic double layer repulsion due to Coulombic forces); 2) steric stabilization (osmotic repulsion occurs when the layers of macromolecules on approaching particles overlap); and 3) electrosteric stabilization (the combination of electrostatic and steric repulsions. In some cases, network stabilization may also refer to particle separation due to the formation of a dense viscous gel matrix between two particles due to hydrogen bonding and polymer entanglements, which may occur at high doses of large viscous macromolecules (Comba and Sethi, 2009). However, it is probably more accurate to refer to this type of particles as networked or bridged nanoparticles because they often appear as large flocs that settle by gravity and cannot form a stable suspension.

Stabilizers may be introduced into a dispersion before or after the aggregates are formed, which are termed as preagglomeration and post-agglomeration stabilization, respectively (Fig. 2). For pre-agglomeration stabilization, stabilizers are added before or during the nucleation and growth and aging of nanoparticles, and thus, preagglomeration stabilization often results in smaller and more uniform nanoparticles. For example, highly stable stabilized ZVI nanoparticles were prepared in the presence $\mathrm{CMC}$ as a stabilizer (Fig. 2). In contrast, in postagglomeration stabilization, the stabilizers are applied after the aggregates of nanoparticles are formed, where the formed aggregates are broken into finer particles via external energy (e.g., sonication) in the presence of a stabilizer. In this case, the size of the resulting particles will be dependent on efficiency of the aggregate breakage, and thus, post-agglomeration stabilization is often less efficient than pre-agglomeration approach in terms of both particle size and reactivity. For instance, Cho and Choi (2010) found that pre-agglomeration stabilized ZVI nanoparticles were more reactive than bare ZVI particles when tested for dechlorination of chlorinated solvents, whereas Phenrat et al. (2009) reported that the post-agglomeration stabilization did not enhance the reactivity of bare nZVI. In addition, for reactive nanoparticles like ZVI, the sonication process could also induce elevated corrosion of the particles, resulting in significant reactivity loss (Tratnyek et al., 2011).

\subsection{Effect of stabilizer on particle reactivity for target contaminants}

In a typical aqueous suspension, stabilizer molecules will distribute between the aqueous phase and the nanoparticle surface. As shown in Fig. 3, stabilizers can influence the interactions between nanoparticles and a target contaminant in a number of ways. First, adsorption of stabilizers on the particle surface can alter the surface properties, such as the surface charge/potential and accessibility. As a result, the modified surface becomes more selective toward different contaminants. For example, coating negatively charged $\mathrm{CMC}$ on $\mathrm{Fe}_{3} \mathrm{O}_{4}$ or Fe-Mn binary nanoparticles turned the surface much more negative than that for starchmodified counterparts. Consequently, starch-modified nanoparticles showed more favorable adsorption for arsenate (An and Zhao, 2012; Liang et al., 2012; Liang and Zhao, 2014); conversely, CMC-stabilized FeS nanoparticles were more favorable for taking up cationic heavy metals such as $\mathrm{Hg}^{2+}$ (Gong et al., 2014). Second, stabilizer
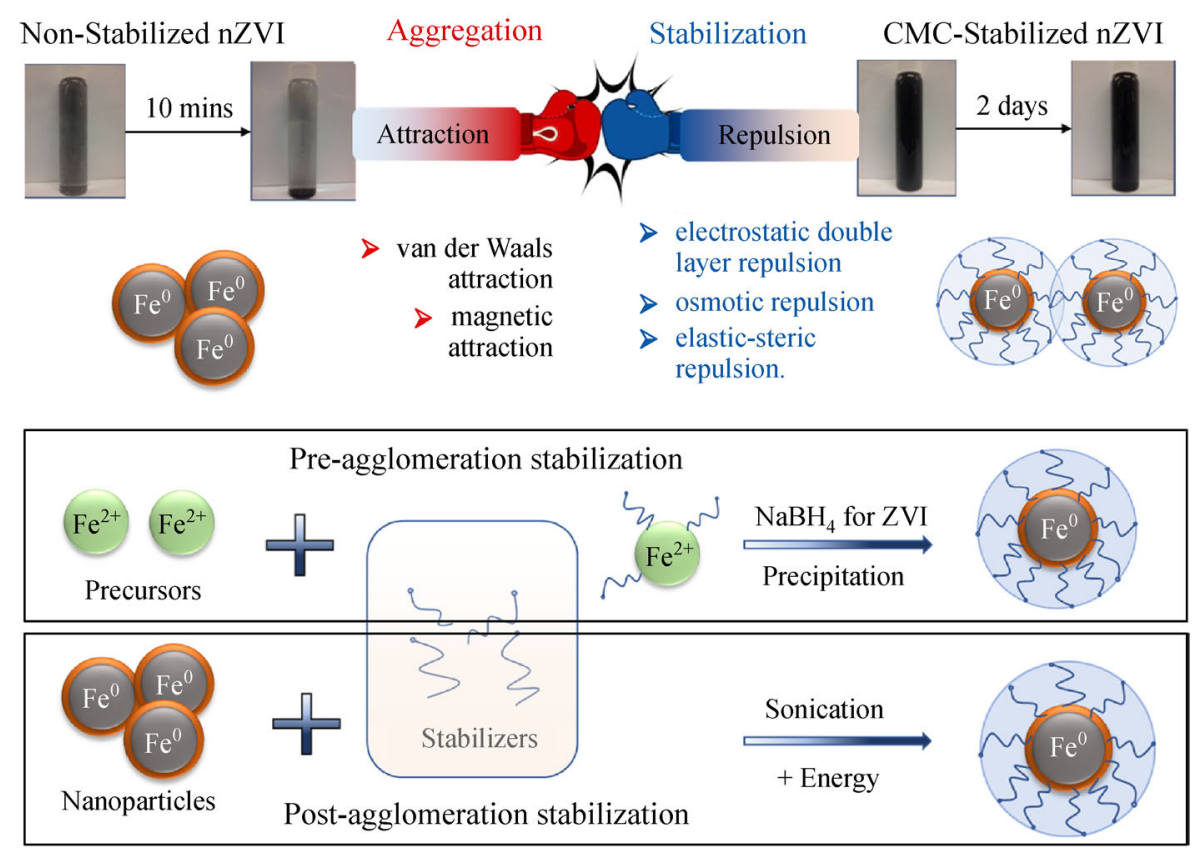

Fig. 2 Conceptualized illustration of nanoparticle aggregation and stabilization. 


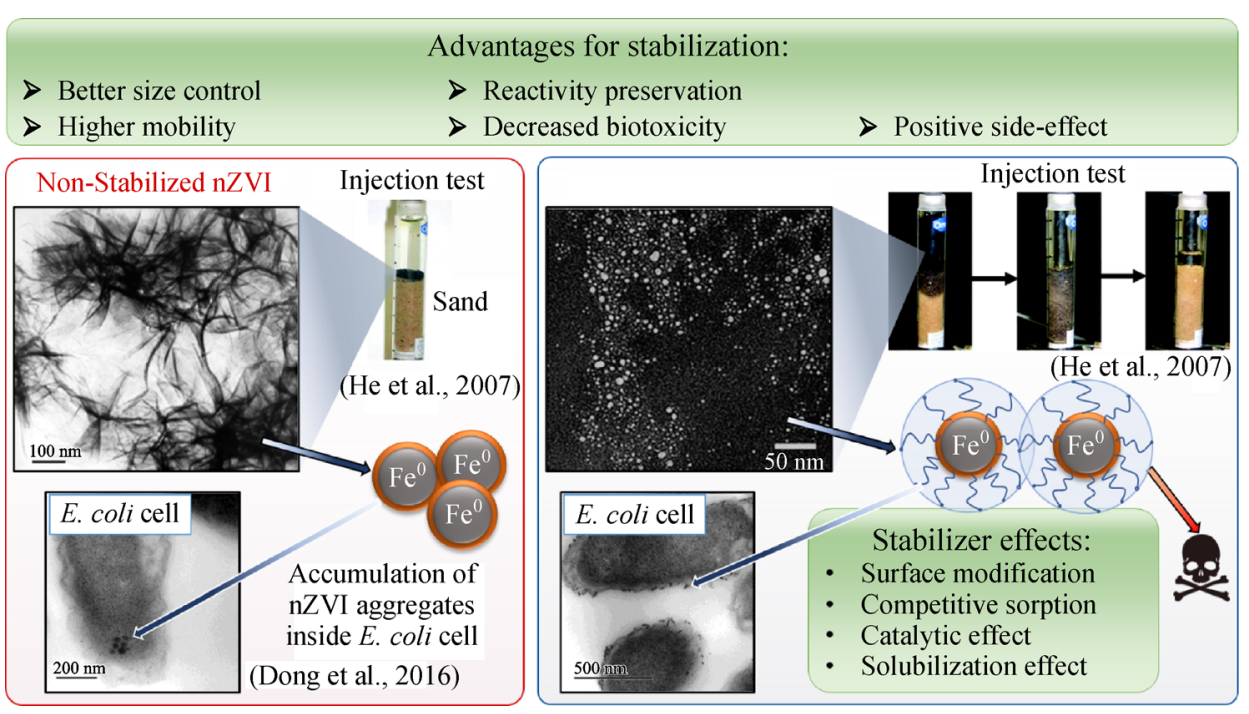

Fig. 3 Effects of stabilizers on interactions between nanoparticles and target contaminants.

molecules may compete with the target contaminants for the adsorption/reaction sites on the nanoparticle surface, or adsorption of stabilizers may block some of the reactive sites or render the sites less accessible. This is particularly the case when small-molecule stabilizers are used. For instance, previous studies on stabilized $\mathrm{Pd}, \mathrm{Fe}-\mathrm{Pd}$ and $\mathrm{FeS}$ nanoparticles indicated that glucose-modified Pd nanoparticles were less reactive as a catalyst than CMC-stabilized $\mathrm{Pd}$ because the adsorbed glucose layer was much denser than the CMC layer (He and Zhao, 2008; Gong et al., 2014). Moreover, the presence of too much stabilizer on the particle surface can inhibit the contaminant mass transfer and reactivity (Gong et al., 2014). Third, some organic stabilizers (especially those with quinone and phenol moieties) may serve as a catalyst or electron shuttle to facilitate redox reactions between the nanoparticles (e.g., ZVI and FeS) and the contaminants (Tratnyek et al., 2011). Lastly, while most stabilizer molecules are expected to be adsorbed on the surface, some remain dissolved in the solution. These free molecules can complex with the target contaminants (e.g., CMC- $\mathrm{Hg}^{2+}$ ), resulting in increased solubility/mobility of the target chemicals.

The overall effects of stabilizers are the sum of all the interactions. Therefore, the selection of the most suitable stabilizer should consider a number of factors, including type of the nanoparticles, properties of the target contaminants, stabilizer molecular size, charge, and functional groups, environmental friendliness, and cost. When used for soil or groundwater remediation, environmental factors including soil properties, particle deliverability, and fate and transport of the stabilizers and nanoparticles, should be taken into account as well.

\subsection{Common types of stabilizers}

For environmental remediation uses, stabilizers can be divided into five groups (Zhao et al., 2016): 1) surfactants;
2) synthetic or natural macromolecules or polyelectrolytes; 3) viscosity modifiers; 4) oil emulsifiers; and 5) microscale solid supports or coatings.

Surfactants are widely used surface modifiers to improve the dispersion stability and the mobility of nanoparticles. Both anionic and cationic surfactants can improve the electrostatic repulsion between nanoparticles resulting in enhanced particle stability. Surfactant molecules can exist in the aqueous phase as monomers, aggregates and micelles. Typically, micelles function better to disperse colloids/nanoparticles. However, the formation of micelles requires a dosage higher than the critical micelle concentration, which may impede its practicality for field applications. In addition, the toxicity of surfactants and the possible solubilization effect on problem contaminants should also be considered.

Natural bio-polymers including starch, guar gum, xanthan gum have been used as neutral stabilizers for engineered nanoparticles (Zhao et al., 2016), where particle stabilization is achieved through the steric or network repulsion mechanism. In contrast, engineered functional polymers or macromolecules, such as CMC, poly acrylic acid (PAA), polyaspartate, and poly styrene sulfonate, are all negatively charged, which offer better particle stabilization through concurrent electrostatic and steric repulsion mechanisms. Overall, these bio-polymers or synthetic polymers (especially, polysugars) are not only effective stabilizers for many environmentally relevant nanoparticles (e.g., ZVI, iron oxides, and Pd), but low-cost and environmental friendly. There have been many of these macromolecules available on the market, with different molecular weights (few hundreds to million Daltons), degrees of substitution (DS), and viscosity. The abundant options provide a convenient means to manipulate the nanoparticle growth and size by use of a suitable stabilizer or a combination of two or more different stabilizers.

Some high molecular-weight macromolecules may 
stabilize nanoparticles by increasing the suspension viscosity and network effect. For instance, xanthan gum (Comba and Sethi, 2009) and guar gum (Sakulchaicharoen et al., 2010) have been used as viscosity modifiers to inhibit aggregation of ZVI nanoparticles.

Oil emulsifiers can modify the hydrophobicity of nanoparticles, which are often desirable for remediation of dense non-aqueous phase liquids (DNAPLs). For instance, vegetable oil (along with some surfactants) was introduced in ZVI suspension to facilitate particle delivery and inhibit the particle corrosion in groundwater (Quinn et al., 2005).

Solid supports or protective solid coatings may also keep nanoparticles from aggregating. For instance, $\mathrm{SiO}_{2}$ or Cbased materials (biochar, carbon nanoparticles, and carbon microspheres) have been used to support ZVI nanoparticles (Zheng et al., 2008; Sunkara et al., 2010; Wei et al., 2019), where nanoparticles are embedded on the surface or in the porous structure of the supports. However, such supported nanoparticles are not directly deliverable in soil, and as such, they are more suitable for water treatment or uses in PRBs in groundwater remediation.

Overall, our knowledge on particle stabilization has come a long way. The use of stabilizers, especially in the pre-agglomeration stabilization process, can facilitate formation of well stabilized aqueous suspensions of desired size and reactivity. Depending on the type of nanoparticles and their uses, different stabilizers may be used. To this end, there is a need for engineered stabilizers of controlled molecular weight (MW) and structure, functionality, and viscosity to optimize the performances of the resulting nanoparticles.

\section{Stabilized nanoparticles for degradation of organic pollutants in soil and water}

For environmental cleanup, the most promising uses of stabilized nanoparticles are for in situ remediation of contaminated soil due to the improved soil deliverability of the nanoparticles. In situ degradation of chlorinated solvents using stabilized ZVI nanoparticles has been one of the most studied subjects over the last two decades or so. Early studies showed that bare ZVI particles appear as micron to millimeter scale aggregates, which are hardly mobile or deliverable in soil (Schrick et al., 2004). Since the invention of the starch- and CMC-stabilized ZVI nanoparticles (He and Zhao, 2005; He et al., 2007), a great deal of effort has been devoted to developing various stabilized or surface modified nanoparticles that can be directly delivered into the contaminated soil. As shown in Fig. 3, CMC-stabilized Fe-Pd nanoparticles were transportable through a loamy sand column within $30 \mathrm{~s}$ under gravity, while bare Fe-Pd nanoparticles were completely blocked on top of the sand column (He et al., 2007). In addition, the CMC coating also mitigates adverse effects of the nanoparticels on biota. For instance, Lee et al. (2008) found that bare nZVI may invade and deactivate E.coli cells (Fig. 3), while Dong et al. (2016) reported that the presence of CMC coating reduced the cytotoxicity of ZVI nanoparticles due to surface electrostatic repulsive forces between the CMC-coated particles and the negatively charges cells. In fact, the presence of the polysaccharide stabilizers may induce some fortuitous positive effects. For example, in a pilot-scale study, He et al. (2010) reported that polysaccharide stabilizers (like CMC) could serve as a carbon source to stimulate the local bacteria activity and induce biodegradation of chlorinated solvents after delivery into the subsurface.

\subsection{Reductive degradation of organic pollutants}

Chlorinated solvents are the most widespread organic contaminants and have been listed as the priority contaminants in soil and groundwater (Stroo et al., 2003; Zimmermann et al., 2020). Typical chlorinated solvents include PCE, TCE, 1,1,2-trichloroethane (TCA), chloroform $(\mathrm{CF})$ and other chlorinated aliphatic hydrocarbons (CAHs). ZVI nanoparticles (usually with Pd or another novel or transition metal as the catalyst) have been extensively studied for dechlorination of these chlorinated hydrocarbons. Equations (12)-(13) illustrate the redox

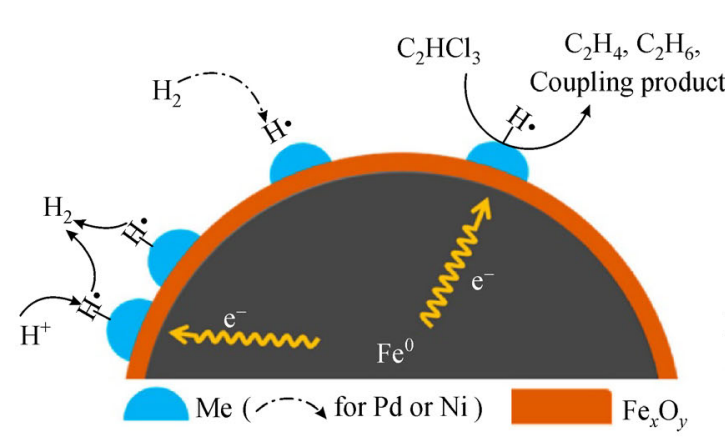

(a)

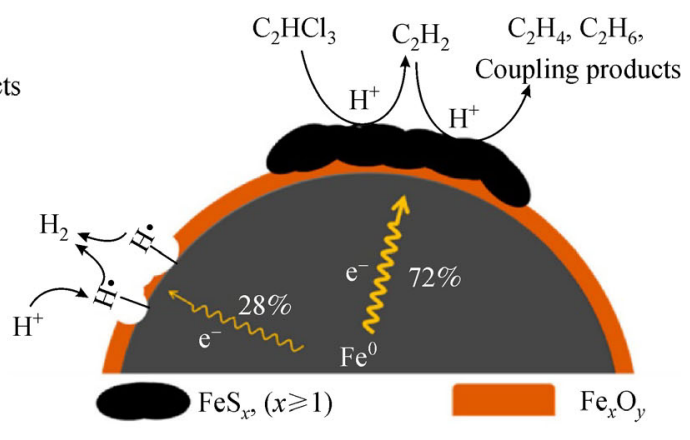

(b)

Fig. 4 Mechanisms of reductive dechlorination of TCE by ZVI-based bimetallic nanomaterials (a) or sulfidated ZVI (b) (He et al., 2018). 
reactions in a typical dechlorination process, and Fig. 4 depicts the reaction mechanisms.

$$
\begin{gathered}
\mathrm{Fe}^{0} \rightarrow \mathrm{Fe}^{2+}+2 \mathrm{e}^{-} \\
E_{0}=-0.44 \mathrm{~V} \text { at } \mathrm{pH} 7 \\
\mathrm{RCl}+2 \mathrm{e}^{-}+\mathrm{H}^{+} \rightarrow \mathrm{RH}+\mathrm{Cl}^{-} \\
E_{0}=0.5-1.5 \mathrm{~V} \text { at } \mathrm{pH} 7
\end{gathered}
$$

Typically, the dechlorination occurs through an initial adsorption followed by reductive breakage of the carbonhalogen bonds. Usually, a small fraction $(\sim 1 \%)$ of a secondary metal such as $\mathrm{Pd}, \mathrm{Ni}$ or $\mathrm{Cu}$ is incorporated on ZVI to catalyze the dechlorination rate. As depicted in Fig. 4(a), the introduction of a metal catalyst can facilitate electron transfer and lead to production of more reactive atomic hydrogen $\left({ }^{\bullet} \mathrm{H}\right)$. In particular, ${ }^{\bullet} \mathrm{H}$ adsorbed on the metal surface was found the predominant contributor to TCE dechlorination (He et al., 2018). In addition, particle stabilization can also speed up the reaction rate. Earlier, He and Zhao (2005) found that starch stabilized Fe-Pd bimetallic nanoparticles showed 37 times faster dechlorination rate for TCE than bare Fe-Pd nanoparticles, and later, the authors found that CMC-stabilized Fe-Pd nanoparticles offered two times faster dechlorination rate than starch-stabilized Fe-Pd nanoparticles due to increased specific surface area and the catalytic activity ( $\mathrm{He}$ and Zhao, 2008). Zhang et al. (2011) reported the first systematic study of degradation of soil-sorbed TCE by CMC-stabilized Fe-Pd nanoparticles and found that the TCE sorbed by soil with higher soil organic matter (SOM) was more recalcitrant to the reductive dechlorination. The possible reasons include: 1) SOM may lessen the stabilizer effect, 2) adsorption of SOM may block the reaction sites for ZVI nanoparticles, 3) SOM may compete with TCE for electron donors, and 4) SOM may suppress the catalytic effect of Pd (Zhang et al., 2011). Moreover, this study demonstrated that the addition of some surfactants can enhance TCE desorption and degradation effectiveness by $\mathrm{CMC}-\mathrm{Fe} / \mathrm{Pd}$, and the overall effect depends on the physiochemical properties of surfactants and soil characteristics (Zhang et al., 2011).

He et al. (2010) conducted a pilot-scale field study on in situ degradation of PCE, TCE and PCBs by delivering $\mathrm{CMC}-\mathrm{Fe} / \mathrm{Pd}$ into the contaminated subsurface. Two injections were administered, and the concentrations of the contaminants were followed for $\sim 600$ days. In the first injection, $\sim 150$ gallons of CMC-Fe/Pd $(0.2 \mathrm{~g} / \mathrm{L})$ were gravity-fed into the $50-\mathrm{ft}(15.2 \mathrm{~m})$ deep unconfined aquifer. After one month, another batch of $\sim 150$ gallons were delivered but at a higher concentration $(1.0 \mathrm{~g} / \mathrm{L})$. Analyses of PCE and TCE in the monitoring wells (located 1.5 and $3.0 \mathrm{~m}$ from the injection well) indicated that PCE and TCE were rapidly degraded with the highest degradation rate occurred in the first week of the injections. The concentrations of the chlorinated solvents rebounded to the pre-injection levels after $\sim 2$ weeks, indicating exhaustion of the ZVI's reactivity. However, the injection of CMC-Fe/Pd initiated a biological dechlorination that started after four weeks of the first injection and lasted throughout the monitoring period. After $\sim 600$ days, the combined concentration of TCE, PCE and their biodegradation byproducts in the two monitoring wells remained $40 \%$ and $61 \%$ lower than the pre-injection level. This was the first field evidence suggesting that $\mathrm{CMC}-\mathrm{Fe} / \mathrm{Pd}$ facilitated a rapid abiotic dechlorination in the early stage and then initiated a long-lasting biotic dechlorination process with $\mathrm{CMC}$ and $\mathrm{H}_{2}$ as additional sources of carbon and electrons.

One of the critical drawbacks of stabilized ZVI nanoparticles has been the relatively short reactive lifetime (hours to days) due to competitive side reactions such as corrosion by water or dissolved oxygen (DO). As such, stabilized ZVI nanoparticles should be prepared on site and used right before an attempt injection. To extend the reactive life and improve the reaction selectivity, S-nZVI have been prepared in recent years (He et al., 2018; Duan et al., 2019a). As shown in Fig. 4(b), the sulfidation may facilitate the electron transfer while suppressing the side corrosion reactions (He et al., 2018). Compared to pristine Fe-Pd, S-nZVI showed a 190 folds faster TCE degradation rate and 36 folds greater electron efficiency (He et al., 2018). He et al. (2018) also claimed that TCE dechlorination is more favorable at the $\mathrm{FeS}_{x}$ sites in S-nZVI, while other side reactions (e.g., corrosion) occur predominantly on the $\mathrm{Fe}_{x} \mathrm{O}_{y}$ sites; specifically, the $\mathrm{FeS}_{x}$ sites contributed $\sim 72 \%$ to the TCE degradation based on the electron utilization efficiency while $\mathrm{Fe}_{x} \mathrm{O}_{y}$ contributed only $\sim 28 \%$. Moreover, S-nZVI degrades TCE mainly through electron transferring on the $\mathrm{FeS}_{x}$ sites, whereas the reactive atomic hydrogen mechanism played only a minor role (He et al. 2018). Fan et al. (2017) pointed out that sulfidation of nZVI may offer the following advantages: 1) it can generate more $\mathrm{FeS}_{x}$ phases thereby enhancing the dechlorination process, 2) sulfidation can suppress the formation of iron oxides on the particle surface resulting in less undesired reactions, and 3) it may immobilize metals by forming sparingly soluble metal sulfides.

Cai et al. (2018b) studied CMC-stabilized ZVI nanoparticles for reductive removal of nitrobenzene (NB) in water and a field soil (Cai et al., 2018b). The materials displayed 3.7 times higher reactivity toward NB degradation than bare ZVI based on the pseudo-first order reaction rate constants $\left(0.643\right.$ vs. $\left.0.175 \mathrm{~min}^{-1}\right)$. The study also revealed that the degradation reaction proceeded as $\mathrm{NB} \rightarrow$ nitrosobenzene $\rightarrow$ phenylhydroxylamine $\rightarrow$ aniline, where aniline is easily biodegradable (Zhao et al., 2019). Moreover, the stabilized nanoparticles at $0.6 \mathrm{~g} / \mathrm{L}$ were able to nearly completely degrade soil-sorbed NB $(0.01 \mathrm{mmol} /$ 
g). By comparing the NB desorption and degradation rates, the availability of electrons was found to be the ratelimiting step in the degradation of soil-sorbed NB.

While stabilized nanoparticles have shown to be a promising remediation technology, there are still several technical issues that need to be addressed. First, although stabilized nanoparticles were initially contemplated to be used for in situ remediation of contaminated soil, most studies so far have been focused on testing the particles' reactivity in the aqueous phase. As such, there exists a data gap on the reactivity and transport behaviors of stabilized nanoparticles when used for treating soil-sorbed organic pollutants. Second, while CMC-stabilized nanoparticles appeared to be most transportable in soil, controlled deliverability of stabilized nanoparticles in the desired source zone remains a challenge, in most cases, the technology is limited by the limited transport distance. Third, more information is needed on the performances of stabilized nanoparticles under actual field conditions, and more pilot- and/or field scale data are yet to be collected to identify the most suitable stabilizers as well as the physical, geological, biogeochemical and hydrodynamic conditions. Fourth, the long-term reactivity, fate and transport of the delivered nanoparticles and the stabilizers need to be investigated. Fifth, the impacts of delivered nanoparticles on the soil physico-chemical properties, the local biogeochemical conditions, and the stability of other co-existing contaminants need to be investigated.

\subsection{Stabilized nanoparticles as a catalyst}

Stabilizers have been widely used in fabricating more reactive catalytic nanoparticles for water or soil treatment. Elemental $\mathrm{Pd}$ is a powerful catalyst and nanosized $\mathrm{Pd}$ particles (with an average size of $2.4 \mathrm{~nm}$ ) were synthesized through a facile $\mathrm{NaBH}_{4}$ reduction method with $\mathrm{CMC}$ as the stabilizer (Liu et al., 2008). The catalytic activities of CMC-stabilized Pd nanoparticles were examined through TCE hydrodechlorination reactions, and the observed pseudo first-order reaction rate constant was increased from 224 to $828 \mathrm{~L} / \mathrm{min} / \mathrm{g}$ and the mean particle size of $\mathrm{Pd}$ decreased from 4.7 to $2.5 \mathrm{~nm}$ when CMC content increased from 0.001 to $0.050 \mathrm{wt} . \%$ (Liu et al., 2008). The work also demonstrated the size-effect and the more active roles of corner and edge atoms of the Pd nanoparticles (Liu et al., 2008). To facilitate water treatment uses of the stabilized Pd nanoparticles, Bacik et al. (2012) loaded CMC-Pd onto a commercial porous $\mathrm{Al}_{2} \mathrm{O}_{3}$ support through an incipient wetness impregnation technique. The CMC-Pd nanoparticles were well-dispersed on the support and composite materials offered $>7$ times greater activity when used for TCE hydrodechlorination compared to commercial alumina supported Pd particles (Zhang et al., 2013). Low concentrations of SOM $(<10 \mathrm{mg} / \mathrm{L})$ exhibited negligible effect on TCE hydrodechlorination, while high concentra- tions of SOM ( $>30 \mathrm{mg} / \mathrm{L})$ decreased the rate constant for nearly $88 \%$ (Zhang et al., 2013). These studies confirmed that $\mathrm{CMC}$ or other similar polysaccharides may serve as effective stabilizers for preparing stable noble metal catalysts. To take advantages of the high catalytic activity of the stabilized nanoparticles, and to facilitate treating contaminants in water in standard reactors (e.g., batch or fixed-bed column), the nanoparticles can be deposited on low-cost supporting materials such as activated alumina and/or activated carbons. High temperature calcination may not be needed although moderate thermal treatment $\left(\sim 300^{\circ} \mathrm{C}\right)$ can consolidate the particle loading and burn off the stabilizer after the loading (Zhang et al., 2013).

\subsection{Oxidative degradation of organic chemicals using stabilized nanoparticles}

PPCPs have been widely detected in groundwater, surface water, and soil owing to their widespread consumption and poor removal efficiency by conventional water treatment processes (Cai et al., 2018a; Hu et al., 2019; Wang et al., 2019). While reductive degradation is often more effective for halogenated organics, oxidation is the common degradation path for many PPCPs. As such, stabilized oxidizing nanoparticles have been prepared and tested to degrade PPCPs in groundwater and soil (Chen et al., 2012; Han et al., 2015; Han et al., 2017b).

$\mathrm{MnO}_{2}$ has been a known oxidant and can oxidize pharmaceuticals (Du et al., 2018). For example, estradiol can be oxidized by $\mathrm{MnO}_{2}$ to form estrone Eq. (14) and 2hydroxyestradiol Eq. (15) (Jiang et al., 2009):

$$
\begin{gathered}
\mathrm{C}_{18} \mathrm{H}_{24} \mathrm{O}_{2}+\mathrm{MnO}_{2}+2 \mathrm{H}^{+} \rightarrow \\
\mathrm{C}_{18} \mathrm{H}_{22} \mathrm{O}_{2}+\mathrm{Mn}^{2+}+2 \mathrm{H}_{2} \mathrm{O} \\
\mathrm{C}_{18} \mathrm{H}_{24} \mathrm{O}_{2}+\mathrm{MnO}_{2}+2 \mathrm{H}^{+} \rightarrow \\
\mathrm{C}_{18} \mathrm{H}_{24} \mathrm{O}_{3}+\mathrm{Mn}^{2+}+\mathrm{H}_{2} \mathrm{O}
\end{gathered}
$$

However, the reaction rate with non-stabilized $\mathrm{MnO}_{2}$ particles is rather slow due to the low specific surface area and limited reactive sites. To enhance the reactivity and facilitate soil deliverability, CMC-stabilized $\mathrm{MnO}_{2}$ nanoparticles were prepared and tested for degradation of aqueous and soil-sorbed 17 $\beta$-estradiol (Han et al., 2015; Han et al., 2017b). The CMC stabilization technique resulted in discrete and rather uniform-sized $\mathrm{MnO}_{2}$ nanoparticles, with a mean particle size of $36.84 \pm 10.17$ $\mathrm{nm}$ at a CMC-to- $\mathrm{MnO}_{2}$ molar ratio of $1.39 \times 10^{-3}$. Moreover, CMC-stabilized $\mathrm{MnO}_{2}$ nanoparticles displayed much greater specific surface area, improved reactivity and improved soil deliverability. For example, when tested for oxidative degradation of estradiol in water, the apparent pseudo first-order rate constant $\left(k_{\mathrm{a}}\right)$ at $\mathrm{pH} 7$ was increased 
from $0.067 \mathrm{~h}^{-1}$ for non-stabilized $\mathrm{MnO}_{2}$ to $0.071 \mathrm{~h}^{-1}$ for CMC-stabilized $\mathrm{MnO}_{2}$, and the $24 \mathrm{~h}$ removal was increased by $9 \%$ (Han et al., 2015). The advantages of stabilized $\mathrm{MnO}_{2}$ nanoparticles became more evident when the nanoparticles were used to degrade soil-sorbed estradiol. After $96 \mathrm{~h}$ of reactions, $83 \%$ of estradiol in a soil slurry system was degraded using $2 \times 10^{-4} \mathrm{~mol} / \mathrm{L}$ of CMC-stabilized $\mathrm{MnO}_{2}$ nanoparticles, while only $70 \%$ of estradiol was degraded by the same dosage of nonstabilized $\mathrm{MnO}_{2}$ particles. The improved reactivity was attributed to the protection of the CMC coating that complexes with inhibitive soil components (such as DOM, $\mathrm{Ca}^{2+}, \mathrm{Mn}^{2+}$, and their complexes). Moreover, CMCstabilized $\mathrm{MnO}_{2}$ displayed much improved soil transportability or deliverability. At a low injection pressure of 2.14 psi, the breakthrough of CMC-stabilized $\mathrm{MnO}_{2}$ through a sandy loam soil bed occurred at $\sim 3$ pore volumes (PVs), and full breakthrough was reached at $\sim 7 \mathrm{PVs}$ with the $C / C_{0}$ plateau maintained at $\sim 0.90$ (i.e. $90 \%$ of the influent level). Stabilized $\mathrm{MnO}_{2}$ nanoparticles were found evenly distributed along the column bed (Han et al., 2015). The soil deliverability enabled the nanoparticles to be used for in situ oxidative degradation of the estradiol or likely other PPCPs sorbed in soil. Up to $88 \%$ of water-leachable $17 \beta-$ estradiol was degraded when an estradiol-laden soil was treated with 22-130 PVs of a CMC-stabilized $\mathrm{MnO}_{2}$ suspension $\left(\mathrm{MnO}_{2}=0.174 \mathrm{~g} / \mathrm{L}\right)$ (Han et al., 2017b).

The degradation involves a first-step adsorption of the solutes on the particle surface and then the oxidation reaction. As such, the degradation effectiveness can be influenced by factors that affect adsorption and reactivity of $\mathrm{MnO}_{2}$, such as particle size, surface area, surface charge, and accessibility of the reactive sites. Lower $\mathrm{pH}$ was found to favor the reaction, which is attributed to the protoncatalyzed reduction of $\mathrm{MnO}_{2}$ via Eq. (16). In addition, lower $\mathrm{pH}$ is associated with higher reduction potential, lower surface charge, and less adsorption of $\mathrm{Mn}^{2+}$ on the particle surface. Some leachable soil components such as $\mathrm{Ca}^{2+}$ and organic matter were found to inhibit the reaction in the early stage, but promoted the reaction in the longer term. The inhibition was due to the rapid uptake of DOM and cations onto the nanoparticles surface, blocking some of the reactive sites; however, over the longer run, DOM may serve as a scavenger for $\mathrm{Mn}^{2+}$ generated in the redoc reaction process, alleviating the inhibitive effect (Han et al., 2015).

$$
1 / 2 \mathrm{MnO}_{2}(\mathrm{~s})+2 \mathrm{H}^{+}+\mathrm{e}^{-} \rightarrow 1 / 2 \mathrm{Mn}^{2+}(\mathrm{aq})+\mathrm{H}_{2} \mathrm{O}
$$

The desorption rate of estradiol from soil was found to critically affect the degradation effectiveness. If the desorption is too fast, it may be flushed away to the downstream of the groundwater by the injected nanoparticle slurry, resulting in limited contact with the nanoparticles; conversely, slow desorption may limit the overall degradation rate. Therefore, the use of the in situ technology must consider the soil properties especially the SOM content and adsorption/desorption behaviors of the contaminants.

It should be noted that $\mathrm{MnO}_{2}$ is a relatively weak oxidant, so it may not completely mineralize PPCPs, rather, it may transform the chemicals into less toxic byproducts. Thus, the $\mathrm{MnO}_{2}$ oxidation may be combined with other processes such as advanced oxidation processes (AOP), if complete mineralization is desired (Du et al., 2018).

Stabilized ZVI nanoparticles may be used to induce Fenton-like reactions under oxic conditions to oxidize organic contaminants in water via reactive oxygen species (ROS) (Joo and Zhao, 2008). Compared to the classical Fenton reactions, the nanoparticle-induced Fenton process can proceed at relatively higher $\mathrm{pH}(>6)$. For instance, Joo and Zhao (2008) prepared and tested CMC-stabilized Fe/ $\mathrm{Pd}$ bimetallic nanoparticles for degradation of lindane and atrazine (Joo and Zhao, 2008). Batch kinetic tests showed that under oxic conditions, the nanoparticles facilitated Fenton-like reactions, which led to oxidation of $65 \%$ of lindane within $10 \mathrm{~min}$ (initial concentration $=1 \mathrm{mg} / \mathrm{L}, \mathrm{ZVI}$ dose $=0.5 \mathrm{~g} / \mathrm{L}, \mathrm{Pd}=0.8 \%$ of $\mathrm{Fe}$, initial $\mathrm{pH}=7.9-8.4$, final $\mathrm{pH}=6.2-6.9$ ). While the particle stabilization greatly enhanced the anaerobic degradation of lindane, the CMC coating was found to consume nearly $50 \%$ of the hydroxyl radicals generated from the nanoparticles-mediated Fenton process, leading to lowered degradation efficiency despite faster reaction rate. Therefore, more oxidation-resistant stabilizers should be explored for this purpose.

Compared to reductive nanoparticles, much less information is available on stabilized oxidative nanoparticles. The degradation pathway of oxidative process is not well understood, and the environmental impacts of the reaction by-products as well as the oxidative nanoparticles need to be investigated. Recent works have indicated that high concentrations of stabilized $\mathrm{Fe}_{3} \mathrm{O}_{4}$ and $\mathrm{FeS}$ nanoparticles under oxic conditions can cause oxidative stress and tissue damage toward zebrafish (Zheng et al., 2018a,b).

More reactive materials are needed, which can either directly extract electrons from the target contaminants or facilitate generation of highly reactive oxidizing species to completely mineralize the target contaminants. While solutions of strong oxidants such as permanganate or persulfate have been used to oxidize soil-sorbed organic contaminants, the solution form of these chemicals bears with some critical limitations, including: 1) the solution may move along with the groundwater and may spread and cause undesired side effects, and 2) due to the limited contact time with the target contaminants, the reactivity may not be well utilized and the effectiveness is severely limited by the desorption rate of the contaminants from the soil. Instead, once delivered, reactive nanoparticles may stay attached to the soil matrix and offer prolonged reactive life without affect the down-gradient flow. The particle 
stabilization technique may also be extended to prepare photoactive materials for oxidative treatment of persistent organic chemicals by preparing photoactive semiconductors in the presence of a stabilizer. For instance, $\mathrm{Xu}$ et al. (2020a) prepared a type of iron oxide/carbon sphere composite material in the presence glucose that serve as both a carbon source and a stabilizer, and the new material showed much enhanced photoactivity toward perfluorooctanoic acid (PFOA).

3.4 Adsorptive removal of persistent organic chemicals using stabilized nanoparticles

Stabilized nanoparticles may also be used for adsorptive removal of persistent organic pollutants (POPs) in water or immobilization of POPs in soil or sediment. Gong et al. (2016b) prepared stabilized magnetite nanoparticles $\left(\mathrm{Fe}_{3} \mathrm{O}_{4}\right)$ for removing PFOA from water. Batch kinetic experiments revealed that the starch-stabilized nanoparticles facilitated fast PFOA uptake with a sorption equilibrium time of $30 \mathrm{~min}$, and provided 2.4 times higher adsorption capacity (maximum Langmuir capacity $=62.5$ $\mathrm{mg} / \mathrm{g}$ ) than non-stabilized magnetite aggregates due to the smaller particle size and larger specific surface area. Fourier transform infrared (FTIR) spectra suggested that the main PFOA removal mechanism was inner-sphere complexation. Moreover, when tested in wheat germination, the starch-stabilized magnetite nanoparticles were able to mitigate the toxic effect of PFOA on the seeding growth. The results demonstrated promise of stabilized $\mathrm{Fe}_{3} \mathrm{O}_{4}$ nanoparticles as a "green" adsorbent for effective removal/immobilization of PFOA in soil and groundwater (Gong et al., 2016b).

Much more work has been done with stabilized nanoparticles for in situ immobilization of metals and metalloids (Liu et al., 2015; Zhao et al., 2016). However, much less information is available for organic chemicals. As adsorption of organic contaminants often involve carbonaceous materials, stabilized carbonaceous materials may be developed. For instance, Liu et al. (2016) prepared stabilized multi-walled carbon nanotubes (MWNTs) using CMC, starch and leonardite humic acid (LHA), and found the stabilization effectiveness ranked as $\mathrm{CMC}>$ starch $>$ LHA. For chemicals of both hydrophobic and lipophobic properties, such as PFOA or perfluorooctanesulfonic acid (PFOS), stabilized composite materials consisting of carbonaceous materials and metal oxides may be developed to induce corporative adsorption mechanisms. For instance, $\mathrm{Xu}$ et al. $(2020 \mathrm{a}, \mathrm{b})$ reported a new class of iron oxide/carbon sphere and carbon-bismuth phosphate composite materials. The composite materials were able to adsorb PFOA through interactions with both the head carboxylic groups and the structural -CF groups instead of the head only or tail only adsorption modes when individual metal oxides or activated carbon are used.

\section{Transport of stabilized nanoparticles}

As stated above, for in situ remediation of soil and groundwater, it is desirable to deliver the nanoparticles into the contaminated source zone, or to create a reactive zone by evenly distributing the nanoparticles in the target space. In general, non-stabilized particles are hardly deliverable in typical soil or sediment due to the strong soil filtration and/or straining effects. As such, proper particle stabilization is required to facilitate direct injection of the reactive nanoparticles into the source zone. This in situ remediation method is particularly advantageous when the contaminants are located deep in the aquifer or when surface remediation actions are not possible (e.g., when a contaminant plume is located under an existing structure). Alternatively, a permeable reactive zone may be built around a contaminant plume to contain its spreading by directly delivering stabilized nanoparticles without digging out the soil. To this end, understanding the transport properties of stabilized nanoparticles that are delivered in the soil is critical to set up the injection points and injection pressure, to assess the effective area, and to evaluate the maximum travel distance of the nanoparticles. It is also noteworthy that the transport behavior, and thus the suitability of the direct injection method, may be affected by the physical and biogeochemical properties of the porous media, such as hydraulic conductivity, mineral compositions, zeta potential, $\mathrm{pH}$, and NOM (Lefevre et al., 2016; Han et al., 2017a; Cai et al., 2018b; Ji et al., 2019).

\subsection{Nanoparticle aggregation and transport theory}

The classical DLVO theory has been widely adopted to interpret the aggregation behavior of nanoparticles (Liu et al., 2016). According to the theory, interactions between nanoparticles are governed by a superposition of van der Waals attractive forces and electrostatic double layer forces. Typically, the van der Waals attractive forces between nanoparticles are approximated by assuming spherical nanoparticles, but the unique shapes and compositions of nanoparticles induce the inaccuracy. Moreover, coating nanoparticles with an organic stabilizer causes additional steric repulsion forces, rendering the particle interactions occur only in the secondary minimum zone. As such, the forces, such as bridging, osmotic, steric, hydrophobic, Lewis acid-base, and magnetic forces, can be of equivalent magnitude as van der Waals attractive forces and electrostatic double layer forces. To deal with the restrictions of the classical model and to take into account the surface heterogeneities, several extended DLVO (XDLVO) models have been developed to evaluate the particle-particle and particle-collector interactions under more realistic conditions and/or in the presence of an organic coating (Phenrat et al., 2007; Hotze et al., 2010).

The transport of nanoparticles in saturated porous media 
is typically interpreted by the filtration theory (Zhang et al., 2017). According to the classical filtration theory, nanoparticles are deposited on porous media following two consecutive steps: 1) transport of nanoparticles to the matrix surface by Brownian diffusion, interception, and gravitational sedimentation, and 2) deposition of the nanoparticles to the matrix surface (Kretzschmar et al., 1999). He et al. (2009) reported the first systematic study on the transport of CMC-stabilized ZVI nanoparticles through various porous media, and reported that Brownian diffusion was the predominant mechanism for the filtration of the nanoparticles, whereas gravitational sedimentation also played an important role, which account for $30 \%$ of the overall single-collector contact efficiency for coarse glass beads and $6.7 \%$ for a sandy soil.

It should be noted that the classical filtration model does not distinguish adsorption from other filtration removal mechanisms, although adsorption can play important roles in the overall removal of the nanoparticles (Han et al., 2017b; Zhang et al., 2017). To overcome this drawback, Zhang et al. (2017) developed a modified transport model by incorporating a Langmuir-type adsorption rate law into the classic convection-dispersion equation. Using experimentally derived adsorption parameters, the model was able to assess the role of adsorption in the transport of CMC-stabilized ZVI nanoparticles. Based on the experimental and modeling data, the filtration removal was found to be primary mechanism for particle retention at low flow velocities, whereas adsorption becomes more significant at elevated flow rates (Zhang et al., 2017).

\subsection{Transport of stabilized nanoparticles in porous media}

Stabilizers can affect the particle size, surface charge and interactions between the nanoparticles and the collectors, and thus affect the particle transportability in porous media (He et al., 2007). Liu et al. (2016) studied effects of CMC, starch and LHA on the aggregation and stabilization of MWCNs in aqueous suspensions. The researchers found that while all three stabilizers inhibited aggregation of the nanoparticles, the stabilization mechanisms differed, namely, the coating of negatively charged $\mathrm{CMC}$ enhanced electrophoretic mobility, the neutral starch slightly curbed electrophoretic mobility, and LHA hardly affected electrophoretic mobility of the particles. Moreover, CMC stabilizes the nanoparticles through enhanced electrostatic repulsion, primary energy barrier and steric hindrance, whereas starch and LHA work primarily through steric hindrance (Liu et al., 2016). Consequently, CMC demonstrated to be the most effective stabilizer. Among various reported commercial stabilizers, CMC exhibited 1-2 orders of magnitude lower attachment efficiency other commercial polymers (He et al., 2009).

Coating of CMC or other polyelectrolytes of higher MW on nanoparticles induces a higher charge density and steric barriers, resulting in enhanced electrosteric repulsion between the nanoparticles. He and Zhao (2007) found that CMCs of higher MW resulted in much smaller ZVI nanoparticles and improved transportability. Saleh et al. (2008) and Liang et al. (2012) tested transport behaviors of ZVI particles modified through the post-agglomeration stabilization approach using a high MW $(125 \mathrm{~kg} / \mathrm{mol})$ poly (methacrylic acid)- $b$-(methyl methacrylate)- $b$-(styrene sulfonate) triblock copolymer, a low MW polyaspartate biopolymer, and the surfactant sodium dodecyl benzene sulfonate $(\mathrm{MW}=348.5 \mathrm{~g} / \mathrm{mol})$. While all the stabilizers rendered the zeta-potential of nZVI more negative, and the stabilizers with larger MW resulted in more negative zetapotential and more transportable ZVI nanoparticles through a sand column. However, caution needs to be exercised that the higher the MW, the more viscous the stabilizer solution, which may impede the transport of nanoparticles in field soil. So far, CMC with MW of 90,000 has been most widely used as a stabilizer for a host of nanoparticles and has been shown most effective.

He et al. (2009) investigated the breakthrough behaviors of CMC-stabilized ZVI nanoparticles (size $=18.1 \pm 2.5$ $\mathrm{nm}$ ) through four saturated model porous media: sandy soil, clean sand, coarse and fine glass beads, and simulated the transport performance using both classical filtration theory and a modified convection-dispersion equation with a first-order removal rate law. A constant concentration plateau $\left(C_{e} / C_{0}\right)$ was observed at full breakthrough, ranging from 0.69 for the soil to 0.99 for glass beads. The particle removal and maximum travel distance $\left(\mathrm{L}_{\max }\right)$ were found strongly dependent on the interstitial flow velocity, but only modestly affected by up to $40 \mathrm{mmol} / \mathrm{L}$ of calcium. $\mathrm{He}$ et al. (2009) also proposed a correlation method to estiamte the $\mathrm{L}_{\max }$ based on flow velocity (or injection pressure). The simulation results indicate that once delivered, $99 \%$ of the nanoparticles are expected to stay in the soil matrix within $16 \mathrm{~cm}$ at a groundwater flow velocity of $0.1 \mathrm{~m} /$ day, but may travel over $146 \mathrm{~m}$ at a flow velocity of $61 \mathrm{~m} / \mathrm{d}$. Later, An et al. (2015) studied tranaport of CMC- or starch-stabilized Fe-Mn binary oxides nanoparticles and found that their transport distance can be harnessed by manipulating the injection pressure or the injection flow rate.

Johnson et al. (2013) investigated transport of CMCstabilized $\mathrm{nZVI}$ in a field-scale large 3D model aquifer $(10 \mathrm{~m} \times 10 \mathrm{~m} \times 2.4 \mathrm{~m}$ deep), and suggested that the veryaggressive flow conditions were necessary to achieve $2.5 \mathrm{~m}$ of nZVI transport using a hydraulically constrained flow path between injection and extraction wells. The authors also indicated that the particle injection altered the groundwater flow, likely due to hydrogen bubble formation, which diverted the nZVI away from the targeted flow path. Using a spectrophotometric method, the authors asserted that deployment of unoxidized nZVI for groundwater remediation would likely be difficult.

The field study by $\mathrm{He}$ et al. (2010) showed that when benchmarked against the bromide tracer, approximately 
$37.4 \%$ and $70.0 \%$ of the injected Fe were detected in the first monitoring well $(1.5 \mathrm{~m}$ from the injection well) following the two injections, confirming the mobility or deliverability of CMC-Fe/Pd under the field soil setting. Moreover, the soil deliverability was further boosted when the injection pressure was elevated.

Bennett et al. (2010) carried out a series of three single well push-pull field tests to investigate the transportability of CMC-nZVI $(0.2$ or $1.0 \mathrm{~g} / \mathrm{L})$ or CMC-Fe/Pd $(0.33 \mathrm{~g} / \mathrm{L})$ in a saturated aquifer. Monitoring the Fe concentration in the extracted groundwater indicated that the stabilized nanoparticles were transportable in the soil, but the mobility dropped with time, possibly due to the soil filtration effect. The results also suggested that the advective nanoparticle transport may be enhanced by circulating the groundwater/ nanoparticle suspension between two wells and by maintaining high post-injection groundwater velocities.

The deviation between the bench-scale laboratory data and some of the larger-scale results can be attributed to many factors, including: 1) heterogeneity of field conditions (e.g., hydraulic conducted, adsorption and filtration characteristics of the soil), 2) particle stabilization conditions (type and concentration of CMC and the nanoparticles), and 3) injection pressure. While sufficiently high injection pressure should be supplied to facilitate particle transport, too high hydraulic pressure may lead to the "caking" effect at the wall of the injection well, leading to clogging the entrance pores. Instead of "pushing" from the injection well, a "pulling" technique may be exercised by extracting groundwater from a monitoring well. In all cases, the bottleneck for the direct injection approach remains to be the insufficient transportability or deliverability. Therefore, more effective particle stabilization strategies are needed. In addition, it is worth noting that the advective delivery (injection) of nanoparticle suspensions pushes away the existing aqueous contaminants without sufficient contact or reaction, and thus, direct injection of nanoparticles is best directed toward the stationary/sorbed contaminants or residual non-aqueous phase liquids within source zones (Bennett et al., 2010).

\subsection{Factors affecting transport of stabilized nanoparticles}

According to the filtration theory, soil retention of nanoparticles involves transport of nanoparticles to the collector's surface and then deposition of particles to the soil matrix. Physical parameters such as surface coating agents, flow velocity, surface properties of soil and nanoparticles, and the accessible surface area can affect the mass transfer of the nanoparticles, whereas the solution and surface chemistry will govern the kinetics of the particle deposition (Kretzschmar et al., 1999; He et al., 2009; Zhang et al., 2017).

The mineral surface of the porous media may interact with stabilizers and/or nanoparticles, thereby affecting adsorption/filtration and transport of nanoparticles (Liu et al., 2013). For instance, Zhang et al. (2017) investigated the effects of aluminum oxide and iron oxide on the transport of CMC-ZVI nanoparticles by column breakthrough experiments, and observed that aluminum oxide and iron oxide coatings on quartz sand enhanced particle retention, reducing the full breakthrough plateau $\left(C / C_{0}\right)$ from 0.90 for plain sand to 0.76 when either of the metal oxides was coated on the sand. Both experimental and modeling resulting confirmed that the presence of both metal oxides increased the adsorption capacity of the nanoparticles, with the $k_{\text {ads }}$ (adsorption coefficient) increased by a factor of $1.6^{-1.8}$, and the $k_{\text {fil }}$ (filtration coefficient) increased by $\sim 2.2$ compared to the plain sand. At lower pore velocities, filtration was the primary mechanism for particle retention; however, at elevated velocities, adsorption became more significant. The presence of NOM (40-80 mg-C/L) and ionic strength (up to $200 \mathrm{mmol} / \mathrm{L} \mathrm{CaCl}_{2}$ ) had negligible effect on the breakthrough profiles of the nanoparticles. While a watersoluble neutral starch was also able to stabilize the nanoparticles, much larger (mean hydrodynamic diameter $=303 \mathrm{~nm}$ ) were obtained, leading to a higher particle retention than CMC-nZVI. Moreover, the narrower pore size and larger specific surface area will result in more collisions, which are favorable for nanoparticle retention through the filtration mechanism. He et al. (2009) reporeted that media with $>1.5$ times greater specific surface area provided $>10 \%$ greater removal efficiency for CMC-stabilized nZVI.

In addition to the material heterogeneity, variation of groundwater flow should be taken into account. Under elevated external pressure, the injected nanoparticle suspension may take a different path from the normal groundwater flow pattern, and sometimes it may be forced to be seeped out from the ground surface (e.g., in the case of shallow and unconfined aquifer).

In some real-world 3D systems, gravity may affect the particle flow pattern especially for metallic nanoparticles. Kanel et al. (2008) tested the 2-D transport of PAAstabilized ZVI nanoparticles through a two-dimensional sand box under saturated, steady-state flow conditions, and found that the nanoparticle plume migrated downward as it moved horizontally through the porous media, indicating that the density gradients influenced on two-dimensional transport. A variable-density groundwater flow model SEAWAT was able to simulate the observed density-driven transport patterns.

Field water matrix and chemistry may alter the physicalchemical properties of the nanoparticles that are observed in the bench scale. For instance, Swindle et al. (2014) compared the size-dependent reactivity of magnetite nanoparticles $(\sim 6 \mathrm{~nm}, \sim 44 \mathrm{~nm}$, and $\sim 90 \mathrm{~nm})$ in a field setting to a laboratory analog. Field results indicated that an organic coating developed on the particle surfaces, which inhibited the reactivity and dissolution of the nanoparticles, with the amount of dissolution decreasing 
as particle size decreased, which reversed the sizedependent reactivity trends observed in laboratory investigations.

NOM may act as a stabilizer or bridging agent affecting particle aggregation and transport (Su, 2017). For instances, the coating of humic acid (HA) was found to lower the $\mathrm{pH}_{\mathrm{PZC}}$ of magnetite nanoparticles, promoting the mobility of nanoparticles in negatively charged soil matrix (Hu et al., 2010). Cuny et al. (2015) reported that adsorption of HA on iron-based nanoparticles induced a more negative zeta potential, which did not alter the particle size but positively affected the particle mobility. However, the details about the impacts of different types and concentrations of HA on the aggregation and transport of nanoparticles are lacking.

Solution $\mathrm{pH}$ and ionic strength play a critical role in the aggregation of nanoparticles by regulating their surface potentials, which may be used to manipulate retention or transport of nanoparticles. For example, the $\mathrm{pH}_{\mathrm{PZC}}$ of nZVI is generally lower than that of soil matrix, thus more nanoparticles may be retained in a soil matrix by adjusting the $\mathrm{pH}$ to a level (e.g., 6.4) where the surfaces of the nanoparticles and soil matrix are positively charged (Kim et al., 2012). It should be noted, however, that too low $\mathrm{pH}$ can cause dissolution of metal-based nanoparticles, and promote undesired corrosion of nZVI (Cai et al., 2018b), while too high $\mathrm{pH}$ may induce metal hydroxides precipitations inhibiting the particle reactivity.

Ionic strength, especially polyvalent cations, is expected to cause double-layer compression and facilitate particle aggregation and collector-particle interactions (Saleh et al., 2008). However, CMC appears to be able to resist such effects common groundwater conditions. For instance, $\mathrm{He}$ et al. (2009) and Zhang et al. (2017) observed that the presence of $\mathrm{Ca}^{2+}$ at up to $40 \mathrm{mmol} / \mathrm{L}$ only moderately affected the transport of CMC-stabilized nZVI. However, much greater effect of ionic strength should be expected for non-stabilized nanoparticles. For instance, Tosco et al. (2012) reporeted that under natural flow conditions, synthetic ferrihydrite nanoparticles were able to transport over 5-30 $\mathrm{m}$ at the normal ionic strength $(2-5 \mathrm{mmol} / \mathrm{L})$ in the tested European aquifers, but only traveled a few meters when the ionic strength was elevated to $10 \mathrm{mmol} / \mathrm{L}$.

\section{Concluding remarks and prospects}

Building upon the classical colloid physics and chemistry, our understanding of stabilized nanoparticles has come a long way in the last two decades or so, and the momentum in their environmental remediation remains strong and diverse, especial in the field of in situ remediation of soil and groundwater. To maintain high reactivity and to facilitate soil deliverability of nanomaterials, various stabilizers and particle stabilization techniques have been investigated through numerous bench- and field-scale studies.

This review overviews the evolution of stabilized nanoparticles with respect to environmental cleanup uses, encompassing the fundamental principles and bench- to field-scale experimentations toward an innovative in situ remediation technology using stabilized nanoparticles. The merits and limitations of the remediation are discussed.

This review also revealed some critical research needs. In addition to the technology gaps mentioned in various sections, the following future research needs are identified:

1) While the particle stabilization technique can greatly improve the soil deliverability of nanoparticles, the transport distance remains a bottle neck for effective application of the technology, especially for soil of low permeability. There is a need to further modify the stabilization technique to facilitate the deliverability and distribution of stabilized nanoparticles into the target contaminated source zones.

2) Other surface modifiers than organic macromolecules should be sought to achieve particle stabilization, extended reactive lifetime and reaction selectivity toward the target contaminants. In this regard, recent works showed that sulfidation of ZVI in combination with CMC stabilization showed both enhanced stability and dechlorination reactivity; and loading sulfur on ZVI enhances particle hydrophobicity and thus selectivity toward hydrophobic compounds. Yet, cautions need to be exercised that the addition of the surface modifiers may increase the particle size and impede the transportability when used for in situ remediation of soil.

3) Information on the long-term effectiveness and reactivity of the injected nanoparticles is lacking. Such long-term monitoring data, especially in the field-scale, are critical for assessing the technology effectiveness and optimizing the process design.

4) Although there has been no evidence showing that stabilized nanoparticles pose significant toxic effects on biota under environmentally relevant conditions and dosages, long-term monitoring data are needed to address the environmental fate and impacts of the nanoparticles delivered in the subsurface. Further studies are needed to investigate how delivered nanoparticles affect the biogeochemical conditions and mobility of other chemicals (especially heavy metals) in the subsurface, in particular under field conditions; likewise, the effects of local environmental conditions on the fate, transport and transformation of the nanoparticles should be investigated.

5) The effect of the delivered nanoparticles on the hydraulic conductivity should be further confirmed at the field scale and over extended period of time.

6) Mechanistically sounder transport model that couples adsorption/desorption and chemical transformation rates is needed for better predicting remediation time and the transport and fate of stabilized nanoparticles in soil. 
7) While many studies have revealed the promise that stabilized nanoparticles may enhance microbial degradation of organic contaminants, further cross-disciplinary studies are needed to understand the synergistic or antagonistic interactions of stabilized nanoparticles and microbial activities to facilitate more efficient application of the technology.

8) More field work is needed to determine the most suitable field conditions (soil properties and geology, groundwater flow characteristics and water chemistry) and to assess the effects of environmental parameters on the effectiveness of the nanomaterials. The information is essential for scaling up treatment designs derived from bench-scale experiments.

9) While the in situ remediation technology holds the potential to be more cost-effective and can treat contaminated aquifers that cannot be by other existing technologies, a comprehensive cost-benefit analysis approach is needed to justify the economic and technical feasibility, as well as the environmental benefits.

10) The applicability of stabilized nanoparticles in unsaturated media needs to be investigated.

11) While stabilized nanoparticles may not be suitable for treating contaminants in water due to separation issues, they may be loaded on high-surface area porous supports such as activated alumina or carbons. Alternatively, bridged or networked nanoparticles may be developed by using large polymeric bridging agents or $\mathrm{CMC} /$ starch at low concentrations.

Acknowledgements This work was partially supported by the Auburn University IGP Program, the National Natural Science Foundation of China (No. 41807340) and the Guangdong Innovative and Entrepreneurial Research Team Program (No. 2016ZT06N569).

Open Access This article is licensed under a Creative Commons Attribution 4.0 International License, which permits use, sharing, adaptation, distribution and reproduction in any medium or format, as long as you give appropriate credit to the original author(s) and the source, provide a link to the Creative Commons licence, and indicate if changes were made. The images or other third party material in this article are included in the article's Creative Commons licence, unless indicated otherwise in a credit line to the material. If material is not included in the article's Creative Commons licence and your intended use is not permitted by statutory regulation or exceeds the permitted use, you will need to obtain permission directly from the copyright holder. To view a copy of this licence, visit http://creativecommons.org/licenses/by/4.0/.

\section{References}

An B, Xie W, Zhao D (2015). Advances in the Environmental Biogeochemistry of Manganese Oxides. Washington, DC: American Chemical Society, 155-168

An B, Zhao D (2012). Immobilization of As(III) in soil and groundwater using a new class of polysaccharide stabilized Fe-Mn oxide nanoparticles. Journal of Hazardous Materials, 211-212: 332-341

Anderson P (1956). On the ion adsorption properties of synthetic magnetite. Harwell, Berks: Gt. Brit. A tomic Energy Research
Establishment

Azzellino A, Colombo L, Lombi S, Marchesi V, Piana A, Andrea M, Alberti L (2019). Groundwater diffuse pollution in functional urban areas: The need to define anthropogenic diffuse pollution background levels. Science of the Total Environment, 656: 1207-1222

Bacik D B, Zhang M, Zhao D, Roberts C B, Seehra M S, Singh V, Shah N (2012). Synthesis and characterization of supported polysugarstabilized palladium nanoparticle catalysts for enhanced hydrodechlorination of trichloroethylene. Nanotechnology, 23(29): 294004

Barnes K K, Kolpin D W, Furlong E T, Zaugg S D, Meyer M T, Barberd L B (2008). A national reconnaissance of pharmaceuticals and other organic wastewater contaminants in the United States-I) Groundwater. Science of the Total Environment, 402(2-3): 192-200

Bennett P, He F, Zhao D, Aiken B, Feldman L (2010). In situ testing of metallic iron nanoparticle mobility and reactivity in a shallow granular aquifer. Journal of Contaminant Hydrology, 116(1-4): 3546

Cai Z, Dwivedi A D, Lee W N, Zhao X, Liu W, Sillanpää M, Zhao D, Huang C H, Fu J (2018a). Application of nanotechnologies for removing pharmaceutically active compounds from water: development and future trends. Environmental Science. Nano, 5(1): 27-47

Cai Z, Fu J, Du P, Zhao X, Hao X, Liu W, Zhao D (2018b). Reduction of nitrobenzene in aqueous and soil phases using carboxymethyl cellulose stabilized zero-valent iron nanoparticles. Chemical Engineering Journal, 332: 227-236

Chen J, Qiu X, Fang Z, Yang M, Pokeung T, Gu F, Cheng W, Lan B (2012). Removal mechanism of antibiotic metronidazole from aquatic solutions by using nanoscale zero-valent iron particles. Chemical Engineering Journal, 181-182: 113-119

Cho Y, Choi S I (2010). Degradation of PCE, TCE and 1,1,1-TCA by nanosized FePd bimetallic particles under various experimental conditions. Chemosphere, 81(7): 940-945

Comba S, Sethi R (2009). Stabilization of highly concentrated suspensions of iron nanoparticles using shear-thinning gels of xanthan gum. Water Research, 43(15): 3717-3726

Cuny L, Herrling M P, Guthausen G, Horn H, Delay M (2015). Magnetic resonance imaging reveals detailed spatial and temporal distribution of iron-based nanoparticles transported through water-saturated porous media. Journal of Contaminant Hydrology, 182: 51-62

Dong H, Xie Y, Zeng G, Tang L, Liang J, He Q, Zhao F, Zeng Y, Wu Y (2016). The dual effects of carboxymethyl cellulose on the colloidal stability and toxicity of nanoscale zero-valent iron. Chemosphere, 144: 1682-1689

Du P, Chang J, Zhao H, Liu W, Dang C, Tong M, Ni J, Zhang B (2018). Sea-buckthorn-like $\mathrm{MnO}_{2}$ decorated titanate nanotubes with oxidation property and photocatalytic activity for enhanced degradation of $17 \beta$-estradiol under solar light. ACS Applied Energy Materials, 1(5): 2123-2133

Duan J, Ji H, Liu W, Zhao X, Han B, Tian S, Zhao D (2019a). Enhanced immobilization of U(VI) using a new type of FeS-modified $\mathrm{Fe}^{0}$ coreshell particles. Chemical Engineering Journal, 359: 1617-1628

Duan J, Ji H, Zhao X, Tian S, Liu X, Liu W, Zhao D (2019b). Immobilization of U(VI) by stabilized iron sulfide nanoparticles: Water chemistry effects, mechanisms, and long-term stability. Chemical Engineering Journal, 124692

Duan L, Naidu R, Thavamani P, Meaklim J, Megharaj M (2015). 
Managing long-term polycyclic aromatic hydrocarbon contaminated soils: A risk-based approach. Environmental Science and Pollution Research International, 22(12): 8927-8941

Elliott D W, Zhang W (2001). Field assessment of nanoscale bimetallic particles for groundwater treatment. Environmental Science \& Technology, 35(24): 4922-4926

Fan D, Lan Y, Tratnyek P G, Johnson R L, Filip J, O'carroll D M, Nunez Garcia A, Agrawal A (2017). Sulfidation of iron-based materials: A review of processes and implications for water treatment and remediation. Environmental Science \& Technology, 51(22): 13070-13085

Gong Y, Gai L, Tang J, Fu J, Wang Q, Zeng E Y (2017). Reduction of Cr (VI) in simulated groundwater by FeS-coated iron magnetic nanoparticles. Science of the Total Environment, 595: 743-751

Gong Y, Liu Y, Xiong Z, Zhao D (2014). Immobilization of mercury by carboxymethyl cellulose stabilized iron sulfide nanoparticles: Reaction mechanisms and effects of stabilizer and water chemistry. Environmental Science \& Technology, 48(7): 3986-3994

Gong Y, Tang J, Zhao D (2016a). Application of iron sulfide particles for groundwater and soil remediation: A review. Water Research, 89: 309-320

Gong Y, Wang L, Liu J, Tang J, Zhao D (2016b). Removal of aqueous perfluorooctanoic acid (PFOA) using starch-stabilized magnetite nanoparticles. Science of the Total Environment, 562: 191-200

Gong Y, Zhao D, Wang Q (2018). An overview of field-scale studies on remediation of soil contaminated with heavy metals and metalloids: Technical progress over the last decade. Water Research, 147: 440 460

Guan X H, Sun Y K, Qin H J, Li J X, Lo I M C, He D, Dong H R (2015). The limitations of applying zero-valent iron technology in contaminants sequestration and the corresponding countermeasures: The development in zero-valent iron technology in the last two decades (1994-2014). Water Research, 75: 224-248

Han B, Liu W, Zhao X, Cai Z Q, Zhao D Y (2017a). Transport of multiwalled carbon nanotubes stabilized by carboxymethyl cellulose and starch in saturated porous media: Influences of electrolyte, clay and humic acid. Science of the Total Environment, 599-600: 188-197

Han B, Zhang M, Zhao D (2017b). In-situ degradation of soil-sorbed $17 \beta$-estradiol using carboxymethyl cellulose stabilized manganese oxide nanoparticles: Column studies. Environmental Pollution, 223: $238-246$

Han B, Zhang M, Zhao D, Feng Y (2015). Degradation of aqueous and soil-sorbed estradiol using a new class of stabilized manganese oxide nanoparticles. Water Research, 70: 288-299

He F, Li Z, Shi S, Xu W, Sheng H, Gu Y, Jiang Y, Xi B (2018). Dechlorination of excess trichloroethene by bimetallic and sulfidated nanoscale zero-valent iron. Environmental Science \& Technology, 52(15): 8627-8637

He F, Zhang M, Qian T W, Zhao D Y (2009). Transport of carboxymethyl cellulose stabilized iron nanoparticles in porous media: Column experiments and modeling. Journal of Colloid and Interface Science, 334(1): 96-102

He F, Zhao D (2005). Preparation and characterization of a new class of starch-stabilized bimetallic nanoparticles for degradation of chlorinated hydrocarbons in water. Environmental Science \& Technology, 39(9): 3314-3320
He F, Zhao D (2007). Manipulating the size and dispersibility of zerovalent iron nanoparticles by use of carboxymethyl cellulose stabilizers. Environmental Science \& Technology, 41(17): 62166221

He F, Zhao D (2008). Hydrodechlorination of trichloroethene using stabilized Fe-Pd nanoparticles: Reaction mechanism and effects of stabilizers, catalysts and reaction conditions. Applied Catalysis B: Environmental, 84(3-4): 533-540

He F, Zhao D, Liu J, Roberts C B (2007). Stabilization of Fe-Pd nanoparticles with sodium carboxymethyl cellulose for enhanced transport and dechlorination of trichloroethylene in soil and groundwater. Industrial \& Engineering Chemistry Research, 46(1): 29-34

He F, Zhao D, Paul C (2010). Field assessment of carboxymethyl cellulose stabilized iron nanoparticles for in situ destruction of chlorinated solvents in source zones. Water Research, 44(7): 23602370

Hoag G E, Collins J B, Holcomb J L, Hoag J R, Nadagouda M N, Varma R S (2009). Degradation of bromothymol blue by 'greener' nanoscale zero-valent iron synthesized using tea polyphenols. Journal of Materials Chemistry, 19(45): 8671-8677

Hotze E M, Phenrat T, Lowry G V (2010). Nanoparticle aggregation: Challenges to understanding transport and reactivity in the environment. Journal of Environmental Quality, 39(6): 1909-1924

Hu J D, Zevi Y, Kou X M, Xiao J, Wang X J, Jin Y (2010). Effect of dissolved organic matter on the stability of magnetite nanoparticles under different $\mathrm{pH}$ and ionic strength conditions. Science of the Total Environment, 408(16): 3477-3489

Hu P, Guo C, Zhang Y, Lv J, Zhang Y, Xu J (2019). Occurrence, distribution and risk assessment of abused drugs and their metabolites in a typical urban river in north China. Frontiers of Environmental Science \& Engineering, 13: 56 https://doi.org/10.1007/s11783-0191140-5

Jeong H Y, Hayes K F (2007). Reductive dechlorination of tetrachloroethylene and trichloroethylene by mackinawite $(\mathrm{FeS})$ in the presence of metals: Reaction rates. Environmental Science \& Technology, 41(18): 6390-6396

Ji H D, Zhu Y M, Liu W, Bozack M J, Qian T W, Zhao D Y (2019). Sequestration of pertechnetate using carboxymethyl cellulose stabilized FeS nanoparticles: Effectiveness and mechanisms. Colloids and Surfaces. A, Physicochemical and Engineering Aspects, 561: $373-380$

Jiang L, Huang C, Chen J, Chen X (2009). Oxidative transformation of $17 \beta$-estradiol by $\mathrm{MnO}_{2}$ in aqueous solution. Archives of Environmental Contamination and Toxicology, 57(2): 221-229

Johnson R L, Nurmi J T, O'Brien Johnson G S, Fan D M, O'Brien Johnson R L, Shi Z, Salter-Blanc A J, Tratnyek P G, Lowry G V (2013). Field-scale transport and transformation of carboxymethylcellulose-stabilized nano zero-valent iron. Environmental Science \& Technology, 47(3): 1573-1580

Joo S H, Zhao D (2008). Destruction of lindane and atrazine using stabilized iron nanoparticles under aerobic and anaerobic conditions: Effects of catalyst and stabilizer. Chemosphere, 70(3): 418-425

Kanel S R, Goswami R R, Clement T P, Barnett M O, Zhao D (2008). Two dimensional transport characteristics of surface stabilized zerovalent iron nanoparticles in porous media. Environmental Science \& Technology, 42(3): 896-900 
Karn B, Kuiken T, Otto M (2009). Nanotechnology and in situ remediation: A review of the benefits and potential risks. Environmental Health Perspectives, 117(12): 1813-1831

Kim E J, Kim J H, Azad A M, Chang Y S (2011). Facile synthesis and characterization of $\mathrm{Fe} / \mathrm{FeS}$ nanoparticles for environmental applications. ACS Applied Materials \& Interfaces, 3(5): 1457-1462

Kim E J, Murugesan K, Kim J H, Tratnyek P G, Chang Y S (2013). Remediation of trichloroethylene by FeS-coated iron nanoparticles in simulated and real groundwater: Effects of water chemistry. Industrial \& Engineering Chemistry Research, 52(27): 9343-9350

Kim H J, Phenrat T, Tilton R D, Lowry G V (2012). Effect of kaolinite, silica fines and $\mathrm{pH}$ on transport of polymer-modified zero valent iron nano-particles in heterogeneous porous media. Journal of Colloid and Interface Science, 370(1): 1-10

Kretzschmar R, Borkovec M, Grolimund D, Elimelech M (1999). Mobile subsurface colloids and their role in contaminant transport. Advances in Agronomy, 66(66): 121-193

Lee C, Kim J Y, Lee W I, Nelson K L, Yoon J, Sedlak D L (2008). Bactericidal effect of zero-valent iron nanoparticles on Escherichia coli. Environmental Science \& Technology, 42(13): 4927-4933

Lefevre E, Bossa N, Wiesner M R, Gunsch C K (2016). A review of the environmental implications of in situ remediation by nanoscale zero valent iron (nZVI): Behavior, transport and impacts on microbial communities. Science of the Total Environment, 565: 889-901

Liang Q, Zhao D (2014). Immobilization of arsenate in a sandy loam soil using starch-stabilized magnetite nanoparticles. Journal of Hazardous Materials, 271: 16-23

Liang Q, Zhao D, Qian T, Freeland K, Feng Y (2012). Effects of stabilizers and water chemistry on arsenate sorption by polysaccharide-stabilized magnetite nanoparticles. Industrial \& Engineering Chemistry Research, 51(5): 2407-2418

Liu C, Chen X, Mack E E, Wang S, Du W, Yin Y, Banwart S A, Guo H (2019). Evaluating a novel permeable reactive bio-barrier to remediate PAH-contaminated groundwater. Journal of Hazardous Materials, 368: 444-451

Liu J, He F, Durham E, Zhao D, Roberts C B (2008). Polysugarstabilized Pd nanoparticles exhibiting high catalytic activities for hydrodechlorination of environmentally deleterious trichloroethylene. Langmuir, 24(1): 328-336

Liu R, Zhao D (2007). Reducing leachability and bioaccessibility of lead in soils using a new class of stabilized iron phosphate nanoparticles. Water Research, 41(12): 2491-2502

Liu R, Zhao D (2013). Synthesis and characterization of a new class of stabilized apatite nanoparticles and applying the particles to in situ $\mathrm{Pb}$ immobilization in a fire-range soil. Chemosphere, 91(5): 594-601

Liu W, Tian S, Zhao X, Xie W, Gong Y, Zhao D (2015). Application of stabilized nanoparticles for in situ remediation of metal-contaminated soil and groundwater: A critical review. Current Pollution Reports, 1(4): 280-291

Liu W, Zhao X, Cai Z, Han B, Zhao D (2016). Aggregation and stabilization of multiwalled carbon nanotubes in aqueous suspensions: influences of carboxymethyl cellulose, starch and humic acid. RSC Advances, 6(71): 67260-67270

Liu Y, Zhang C, Hu D, Kuhlenschmidt M S, Kuhlenschmidt T B, Mylon S E, Kong R, Bhargava R, Nguyen T H (2013). Role of collector alternating charged patches on transport of cryptosporidium parvum oocysts in a patchwise charged heterogeneous micromodel. Environmental Science \& Technology, 47(6): 2670-2678

Mazloomi S, Nasseri S, Nabizadeh R, Yaghmaeian K, Alimohammadi K, Nazmara S, Mahvi A H (2016). Remediation of fuel oil contaminated soils by activated persulfate in the presence of $\mathrm{MnO}_{2}$. Soil and Water Research, 11(2): 131-138

Mcmanus S L, Coxon C, Mellander P E, Richards K G (2017). Hydrogeological characteristics influencing the occurrence of pesticides and pesticide metabolites in groundwater across the Republic of Ireland. Science of The Total Environment, 601-602: 594-602

MEE (2016). 2015 China's Environmental Conditions Report. Beijing: Ministry of Ecology and Environmental Protection of the People's Republic of China

Moran M J, Zogorski J S, Squillace P J (2007). Chlorinated solvents in groundwater of the United States. Environmental Science \& Technology, 41(1): 74-81

MWR (2015). China's Water Resource Bulletin 2014. Beijing: Ministry of Water Resource of China

Njagi E C, Huang H, Stafford L, Genuino H, Galindo H M, Collins J B, Hoag G E, Suib S L (2011). Biosynthesis of iron and silver nanoparticles at room temperature using aqueous sorghum bran extracts. Langmuir, 27(1): 264-271

O'Carroll D, Sleep B, Krol M, Boparai H, Kocur C (2013). Nanoscale zero valent iron and bimetallic particles for contaminated site remediation. Advances in Water Resources, 51: 104-122

O'Connor D, Hou D Y, Ok Y S, Song Y N, Sarmah A K, Li X R, Tack F M G (2018). Sustainable in situ remediation of recalcitrant organic pollutants in groundwater with controlled release materials: A review. Journal of Controlled Release, 283: 200-213

O'Hannesin S F, Gillham R W (1992). A permeable reaction wall for in situ degradation of halogenated organic compounds. Toronto, Ontario, Canada

Obiri-Nyarko F, Grajales-Mesa S J, Malina G (2014). An overview of permeable reactive barriers for in situ sustainable groundwater remediation. Chemosphere, 111: 243-259

Phenrat T, Liu Y, Tilton R D, Lowry G V (2009). Adsorbed polyelectrolyte coatings decrease $\mathrm{Fe}^{0}$ nanoparticle reactivity with TCE in water: Conceptual model and mechanisms. Environmental Science \& Technology, 43(5): 1507-1514

Phenrat T, Saleh N, Sirk K, Kim H J, Tilton R D, Lowry G V (2008). Stabilization of aqueous nanoscale zerovalent iron dispersions by anionic polyelectrolytes: Adsorbed anionic polyelectrolyte layer properties and their effect on aggregation and sedimentation. Journal of Nanoparticle Research, 10(5): 795-814

Phenrat T, Saleh N, Sirk K, Tilton R D, Lowry G V (2007). Aggregation and sedimentation of aqueous nanoscale zerovalent iron dispersions. Environmental Science \& Technology, 41(1): 284-290

Quinn J, Geiger C, Clausen C, Brooks K, Coon C, O'hara S, Krug T, Major D, Yoon W S, Gavaskar A, Holdsworth T (2005). Field demonstration of DNAPL dehalogenation using emulsified zero-valent iron. Environmental Science \& Technology, 39(5): 13091318

Sakulchaicharoen N, O'carroll D M, Herrera J E (2010). Enhanced stability and dechlorination activity of pre-synthesis stabilized nanoscale FePd particles. Journal of Contaminant Hydrology, 
118(3-4): 117-127

Saleh N, Kim H J, Phenrat T, Matyjaszewski K, Tilton R D, Lowry G V (2008). Ionic strength and composition affect the mobility of surfacemodified $\mathrm{Fe}^{0}$ nanoparticles in water-saturated sand columns. Environmental Science \& Technology, 42(9): 3349-3355

Schrick B, Hydutsky B W, Blough J L, Mallouk T E (2004). Delivery vehicles for zerovalent metal nanoparticles in soil and groundwater. Chemistry of Materials, 16(11): 2187-2193

Squillace P J, Moran M J (2007). Factors associated with sources, transport, and fate of volatile organic compounds and their mixtures in aquifers of the United States. Environmental Science \& Technology, 41(7): 2123-2130

Stroo H F, Unger M, Ward C H, Kavanaugh M C, Vogel C, Leeson A, Marqusee J A, Smith B P (2003). Peer reviewed: Remediating chlorinated solvent source zones. Environmental Science \& Technology, 37(11): 224A-230A

Su C M (2017). Environmental implications and applications of engineered nanoscale magnetite and its hybrid nanocomposites: A review of recent literature. Journal of Hazardous Materials, 322: 4884

Sunkara B, Zhan J, He J, Mcpherson G L, Piringer G, John V T (2010). Nanoscale zerovalent iron supported on uniform carbon microspheres for the in situ remediation of chlorinated hydrocarbons. ACS Applied Materials \& Interfaces, 2(10): 2854-2862

Swindle A L, Madden A S E, Cozzarelli I M, Benamara M (2014). Sizedependent reactivity of magnetite nanoparticles: A field-laboratory comparison. Environmental Science \& Technology, 48(19): 1141311420

Tang J, Zhu W, Kookana R, Katayama A (2013) Characteristics of biochar and its application in remediation of contaminated soil. Journal of Bioscience and Bioengineering, 116(6): 653-659

Tosco T, Bosch J, Meckenstock R U, Sethi R (2012). Transport of ferrihydrite nanoparticles in saturated porous media: Role of ionic strength and flow rate. Environmental Science \& Technology, 46(7): 4008-4015

Tratnyek P G, Salter-Blanc A J, Nurmi J T, Amonette J E, Liu J, Wang C, Dohnalkova A, Baer D R (2011). Aquatic Redox Chemistry. Washington, DC: American Chemical Society,381-406

Turner B D, Binning P J, Sloan S W (2008). A calcite permeable reactive barrier for the remediation of fluoride from spent potliner (SPL) contaminated groundwater. Journal of Contaminant Hydrology, 95 (3-4): $110-120$

Vignola R, Bagatin R, De Folly D'Auris A, Flego C, Nalli M, Ghisletti D, Millini R, Sisto R (2011). Zeolites in a permeable reactive barrier (PRB): one year of field experience in a refinery groundwater-part 1 : The performances. Chemical Engineering Journal, 178: 204-209

Wang C B, Zhang W X (1997). Synthesizing nanoscale iron particles for rapid and complete dechlorination of TCE and PCBs. Environmental Science \& Technology, 31(7): 2154-2156

Wang T, Qian T, Zhao D, Liu X, Ding Q (2020). Immobilization of perrhenate using synthetic pyrite particles: Effectiveness and remobilization potential. Science of the Total Environment, 725: 138423

Zhang W, Wang W, Liang H, Gao D (2019). Occurrence and fate of typical antibiotics in wastewater treatment plants in Harbin, Northeast China. Frontiers of Environmental Science \& Engineering, 13:
34 https://doi.org/10.1007/s11783-019-1118-3

Zhang G, Wei J, Luo J, Xue H, Huang D, Cheng Z, Jiang X (2019). Nanoscale zero-valent iron supported on biochar for the highly efficient removal of nitrobenzene. Frontiers of Environmental Science \& Engineering, 13: 61 https://doi.org/10.1007/s11783-019$1142-3$

Wei Y T, Wu S C, Chou C M, Che C H, Tsai S M, Lien H L (2010). Influence of nanoscale zero-valent iron on geochemical properties of groundwater and vinyl chloride degradation: A field case study. Water Research, 44(1): 131-140

WHO (2006). Protecting Groundwater for Health: Managing the Quality of Drinking-Water Sources. Geneva: World Health Organization

Wiesner M, Bottero J Y (2007). Environmental Nanotechnology. New York: McGraw-Hill Professional Publishing

Wu J, Zeng R J (2018). In situ preparation of stabilized iron sulfide nanoparticle-impregnated alginate composite for selenite remediation. Environmental Science \& Technology, 52(11): 6487-6496

Xu T, Ji H, Gu Y, Tong T, Xia Y, Zhang L, Zhao D (2020a). Enhanced adsorption and photocatalytic degradation of perfluorooctanoic acid in water using iron (hydr)oxides/carbon sphere composite. Chemical Engineering Journal, 388: 124230

Xu T, Zhu Y, Duan J, Xia Y, Tong T, Zhang L, Zhao D (2020b). Enhanced photocatalytic degradation of perfluoroocanoic acid using carbon-modified bismuth phosphate composite: Effectiveness, material syntrgy and roles of carbon. Chemical Engineering Journal, 395 : 124991

Zhang M, Bacik D B, Roberts C B, Zhao D (2013). Catalytic hydrodechlorination of trichloroethylene in water with supported CMC-stabilized palladium nanoparticles. Water Research, 47(11): 3706-3715

Zhang M, He F, Zhao D, Hao X (2011). Degradation of soil-sorbed trichloroethylene by stabilized zero valent iron nanoparticles: Effects of sorption, surfactants, and natural organic matter. Water Research, 45(7): 2401-2414

Zhang M, He F, Zhao D Y, Hao X D (2017). Transport of stabilized iron nanoparticles in porous media: Effects of surface and solution chemistry and role of adsorption. Journal of Hazardous Materials, 322: 284-291

Zhao X, Liu W, Cai Z, Han B, Qian T, Zhao D (2016). An overview of preparation and applications of stabilized zero-valent iron nanoparticles for soil and groundwater remediation. Water Research, 100: 245-266

Zhao Y, Lin L, Hong M (2019) Nitrobenzene contamination of groundwater in a petrochemical industry site. Frontiers of Environmental Science \& Engineering, 13: 29. https://doi.org/10.1007/ s11783-019-1107-6

Zheng M, Lu J, Zhao D (2018a). Effects of starch-coating of magnetite nanoparticles on cellular uptake, toxicity and gene expression profiles in adult zebrafish. Science of the Total Environment, 622-623: 930941

Zheng M, Lu J, Zhao D (2018b). Toxicity and transcriptome sequencing (RNA-seq) analyses of adult zebrafish in response to exposure carboxymethyl cellulose stabilized iron sulfide nanoparticles. Scientific Reports, 8: 8083

Zheng T, Zhan J, He J, Day C, Lu Y, Mcpherson G L, Piringer G, John V $\mathrm{T}$ (2008). Reactivity characteristics of nanoscale zerovalent iron- 
silica composites for trichloroethylene remediation. Environmental Science \& Technology, 42(12): 4494-4499

Zimmermann J, Halloran L J S, Hunkeler D (2020). Tracking chlorinated contaminants in the subsurface using compound-specific chlorine isotope analysis: A review of principles, current challenges and applications. Chemosphere, 244: 125476
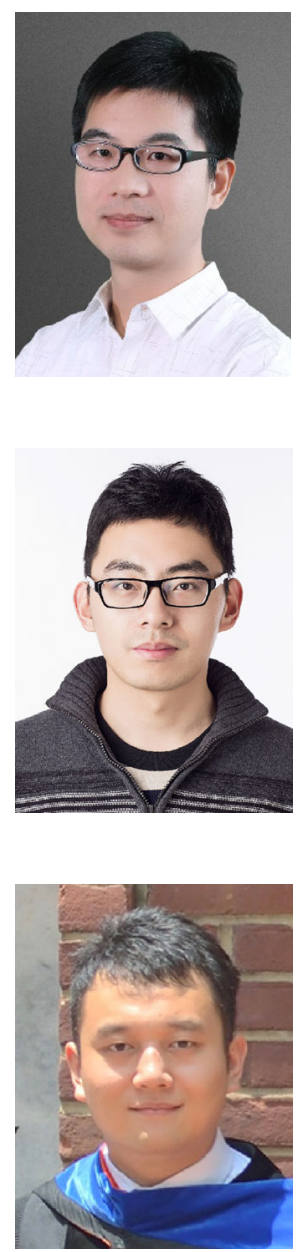

Dr. Zhengqing Cai obtained his Ph.D. in Environmental Engineering from Auburn University in 2016. Following postdoctoral research at Fudan University, he joined the faculty of East China University of Science and Technology in 2018. His research interests focus on the photochemical degradation of organic contaminants and environmental nanotechnologies.

Dr. Xiao Zhao has been an associate professor in the College of Water Resources \& Civil Engineering at China Agricultural University since 2017. He received his $\mathrm{Ph}$. D. from Auburn University, USA, in 2015, and then carried out a postdoctoral study at Tsinghua University. He has published over 35 peer-reviewed articles focusing on environmental nanotechnologies.

Dr. Jun Duan is current a postdoctoral researcher in the college of environmental science and engineering at Peking University. He received his Ph.D. from Auburn University, USA, in 2019. His research interests focus on the synthesis and application of nanomaterials for remediation of contaminated water and soil. He has published 11 peer-reviewed articles.

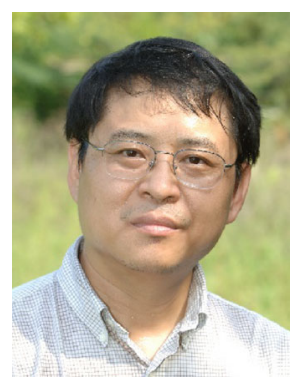

Dr. Dongye Zhao is the Engineering Alumni Chair Professor in the Civil Engineering Department of Auburn University. He received his Ph.D. in environmental engineering from Lehigh University in 1998. His research focuses on development of stabilized nanomaterials for soil/groundwater remediation and photocatalysts for destruction of persistent organic pollutants.

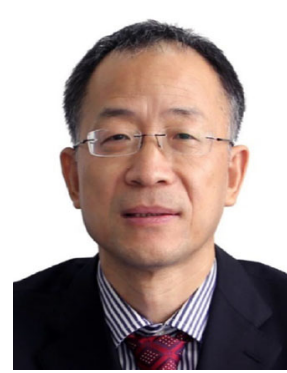

Dr. Zhi Dang is a Professor in the School of Environment and Energy at the South China University of Technology. His research fields are focused on the release, migration, and fate of heavy metals from mining areas and the remediation of soil contaminated by heavy metals.

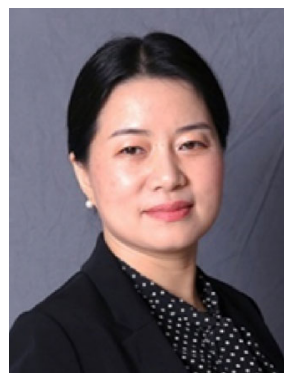

Dr. Zhang Lin is a professor in the School of Environment and Energy at the South China University of Technology. She obtained her Ph.D. from the Institute of Chemistry of the Chinese Academy of Sciences in 1999. Her current research interests are focused on the resources recovery and energy utilization of the solid wastes. 